\title{
Essential fatty acids and the brain: possible health implications
}

\author{
Kuresh A. Youdim*, Antonio Martin, James A. Joseph \\ Laboratory of Neuroscience, United States Department of Agriculture, Jean Mayer Human Nutrition Research Center on Aging at Tufts University, \\ Boston, MA 02111, USA
}

Received 6 July 1999; received in revised form 13 September 1999; accepted 29 September 1999

\begin{abstract}
Linoleic and $\alpha$-linolenic acid are essential for normal cellular function, and act as precursors for the synthesis of longer chained polyunsaturated fatty acids (PUFAs) such as arachidonic (AA), eicosapentaenoic (EPA) and docosahexaenoic acids (DHA), which have been shown to partake in numerous cellular functions affecting membrane fluidity, membrane enzyme activities and eicosanoid synthesis. The brain is particularly rich in PUFAs such as DHA, and changes in tissue membrane composition of these PUFAs reflect that of the dietary source. The decline in structural and functional integrity of this tissue appears to correlate with loss in membrane DHA concentrations. Arachidonic acid, also predominant in this tissue, is a major precursor for the synthesis of eicosanoids, that serve as intracellular or extracellular signals. With aging comes a likely increase in reactive oxygen species and hence a concomitant decline in membrane PUFA concentrations, and with it, cognitive impairment. Neurodegenerative disorders such as Parkinson's and Alzheimer's disease also appear to exhibit membrane loss of PUFAs. Thus it may be that an optimal diet with a balance of n-6 and n-3 fatty acids may help to delay their onset or reduce the insult to brain functions which these diseases elicit. Published by Elsevier Science Ltd.
\end{abstract}

\section{Introduction}

In 1929, Burr and Burr [21] discovered the essentiality in the animal kingdom of the fatty acids linoleic $($ LA $\sim 18: 2 n-6)$ and $\alpha$-linolenic (LNA $\sim 18: 3 n-3$ ) acid. The abbreviations $n-6$ and $n-3$ for these unsaturated fatty acids represent the position of the first double bond when counting from the methyl carbon atom at the distal end of the fatty acid (FA) chain. These FAs and their respective derivatives are also commonly referred to as omega-6 and omega-3 FAs respectively.

Abbreviations: FA, fatty acids; EFAs, essential fatty acids; PUFAs, polyunsaturated fatty acids; LA, linoleic acid; LNA, linolenic acid; DHA, docosahexaenoic acid; AA, arachidonic acid; DGLA, dihomo-gamma linoleic acid; EPA, eicosapentaenoic acid; DPA, docosapentaenoic acid; PE, phosphatidyl ethanolamine; PS, phosphatidyl serine; PC, phosphatidyl choline; PI, phosphatidyl inositol; PD, Parkinson's disease; AD, Alzheimer's disease.

* Corresponding author. Tel.: +1-617-556-3114; fax: +1-617-5563222 .

E-mail address: kyoudim@hnrc.tufts.edu (K.A. Youdim).
Both these FAs are required for synthesis of longchained fatty acids, as they cannot be synthesized de novo and consequently are referred to as essential fatty acids (EFAs). This important finding raised many questions, but in particular the issue about the biochemical and biophysical mechanisms that lead to their essentiality. To date, a multitude of mechanisms have been explored, for example, their effects on; the structural integrity and fluidity of membranes $[33,130]$; enzyme activities [80,120,125]; lipid-protein interactions [117]; and their role as precursors for eicosanoids, such as prostaglandins, leukotrienes and thromboxanes.

The discovery of the important roles played by FAs prompted investigators to determine their requirements for optimal health $[2,34,67]$. In the past, n-3 FAs were only classed as essential because of their ability, albeit very limited as compared to n-6 FAs, to ameliorate some classic symptoms of essential fatty acid deficiency, such as dermatitis [4], growth retardation [162] and reproductive failure [24]. However, n-3 FAs have other roles as suggested by their special prominence in neural and retinal tissues $[3,19,29,84]$. For 
example, they have been reported as having profound influences in the CNS $[25,64,69,99,159]$. In addition, n6 and n-3 PUFAs such as dihomo-gamma-linolenic acid (DGLA 20:3n-6), arachidonic acid (AA 20:4n6) and eicosapentaenoic acid (EPA 20:5n-3) are precursors for eicosanoids biosynthesis [35,108], which can exert a wide range of biological actions [53]. Whilst EPA content of membranes is a source for eicosanoid synthesis, DHA content may also play a contributory role, both directly and indirectly. Although a relatively unexplored field, DHA can function as a source for EPA through a retroconversion reaction, which in turn will be oxygenated to the various eicosanoid metabolites [30]. Direct oxygenated products of DHA, resulting from peroxidative damage have also been identified and are commonly referred to as docosanoids $[5,111,118]$. These DHA derivatives resemble eicosanoids and may provide a source of unique mediators of physiological processes in the CNS, such as that reported in the rat pineal body [118], but in particular the retina [111].

PUFA composition within membranes has also been reported to modulate the efficiency of numerous membrane transporters and enzymes
$[42,99,103,114,128,129,131,143]$. This review is intended to summarize the implications of dietary FA on the biophysical and functional properties of brain membranes, their effects on eicosanoid production, and the possible connections between membrane EFA, aging and oxidative stress with the onset of neurodegenerative diseases.

\section{Dietary sources and synthesis of essential fatty acids}

The recommendations for dietary intake of EFAs are not easy to propose since optimal requirements are not fully known. However, in order to ensure the best biological functions, an intake of about $3-6 \%$ of total fat is generally recommended [13]. Bjerve et al. [13], reported that within the $\mathrm{n}-6$ family, LA is the major EFA and based on animal studies about $1-2 \%$ of total caloric intake is required to relieve symptoms induced by its deficiency. LNA provision at $0.5-1 \%$ of total fat is also required as a source for EPA and DHA synthesis, for neuronal and visual tissues, and during pregnancy and nursing. Thus the requirements of EPA and DHA would be about $0.4 \%$, and according to

Table 1

Dietary fatty acid composition of plant oils and nuts ${ }^{\mathrm{a}}$

\begin{tabular}{|c|c|c|c|c|c|}
\hline \multirow[t]{2}{*}{ Species } & \multirow[t]{2}{*}{ Description } & \multicolumn{3}{|c|}{ Fatty acids (mol\%) } & \multirow[b]{2}{*}{$n-6: n-3$} \\
\hline & & $18: \ln -9$ & $18: 2 n-6$ & $18: 3 n-3$ & \\
\hline Juglans cinerea & Butternut & 19.0 & 61.9 & 16.0 & 3.9 \\
\hline Aleurites moluccana & Candlenut oil & 10.5 & 48.4 & 28.5 & 1.7 \\
\hline Ricinus communis & Castor oil & 3.0 & 4.0 & $\operatorname{tr}$ & $>4.0$ \\
\hline Castanea mollisima & Chestnut & 54.0 & 24.9 & 2.7 & 9.2 \\
\hline Cocos nucifera & Coconut oil & 4.5 & 1.4 & - & - \\
\hline Zea mays L. & Corn oil & 30.5 & 52.0 & 1.0 & 52.0 \\
\hline Gossypium hirsutum & Cottonseed oil & 18.3 & 50.5 & $\operatorname{tr}$ & $>50.5$ \\
\hline$N r$ & Evening primrose oil & 7.5 & 74.9 & - & - \\
\hline Vitis vinifera & Grapeseed oil & 22.0 & 67.0 & 0.9 & 74.4 \\
\hline Cannabis sativa & Hemp seed oil & 12.0 & 55.0 & 25.0 & 2.2 \\
\hline Linum usitaissimum & Linseed oil & 16.6 & 14.2 & 59.8 & 0.24 \\
\hline Brassica alba & White mustard seed oil & 23.2 & 8.9 & 10.4 & 0.85 \\
\hline Olea europea & Olive oil & 78.1 & 7.3 & 0.6 & 12.2 \\
\hline Elaeis giuneensis & African palm oil & 37.7 & 10.6 & 0.2 & 53.0 \\
\hline Carya illioensis & Pecan & 66.9 & 22.1 & 1.1 & 20.1 \\
\hline Papaver somniferium & Poppy seed oil & 11.0 & 72.0 & 5.0 & 14.4 \\
\hline Brassica campestris & Rapeseed oil & 53.5 & 23.5 & 14.0 & 1.68 \\
\hline Carthamus tinctorius & Safflower oil & 13.8 & 75.2 & $\operatorname{tr}$ & $>75.2$ \\
\hline Sesamum indicum & Sesame oil & 38.2 & 45.0 & 0.6 & 75.0 \\
\hline Soja max & Soybean oil & 22.0 & 53.0 & 7.5 & 7.07 \\
\hline Helianthus annus & Sunflower oil & 19.5 & 68.5 & 0.1 & 685 \\
\hline Juglans nigra & Walnut, black & 29.1 & 58.3 & 4.9 & 11.9 \\
\hline Juglans regia & Walnut, English & 19.1 & 57.4 & 13.1 & 4.38 \\
\hline Trittcom aestiuum & Wheat germ oil & 21.8 & 57.9 & 5.1 & 11.4 \\
\hline
\end{tabular}

a Abbreviations: tr: trace amount; 18:1n-9: eicosanoic acid; 18:2n-6: linoleic acid (LA); 18:3n-3: alpha linolenic acid (LNA). Data taken from reviews by Gruger [48], and Salem [116]. 
Bjerve et al. [13] the optimum dietary intake of these EFAs would be around $900 \mathrm{mg} /$ day for EPA and $400 \mathrm{mg} /$ day for DHA.

Plants, particularly seed oils, provide rich sources of triglycerides containing PUFAs, usually of the n-6 family (Table 1). Leafy vegetables and some fruits contribute PUFAs of the n-3 variety, mainly 18:3n-3 [124]. Fresh fish and processed fish oils have been shown to be the major dietary sources of $\mathrm{C} 20$ and $\mathrm{C} 22 \mathrm{n}-3$ PUFAs in the Western diet (Table 2). Consumption of EFAs in sufficient concentrations is of course a limiting factor that determines their concentrations in tissues. Additionally, FAs must first cross the intestinal epithelium before reaching the different tissues, where digestion and absorption constitute further problems in their availability [23]. Carlier et al. [23], showed that the EFAs taken up by tissues are recovered in relatively high proportions as components of phospholipids. The majority of membrane PUFAs are synthesized from dietary LA and LNA, which act as precursors for the synthesis of these longer-chained
PUFAs via a series of desaturation and elongation reactions (Fig. 1) [127,151].

\section{The effects of dietary fats on brain fatty acid composition}

Tinoco [135] reported that the general composition in the phospholipid fractions of the brain contained very little LA. Arachidonic acid was found to be an important component, but the major PUFA present was usually DHA $[73,161]$. High levels of DHA have also been reported in subcellular fractions such as synaptosomes [84,150], synaptic vesicles [155], mitochondria [156], microsomes [128] and nerve growth cones [81].

Modifications of the brain membrane fatty acid composition have been reported with supplementation of various dietary oils $[3,17,36,45,54,62,74,75,84,128$, 133,153,155] (Table 3). Furthermore, changes in PUFA content of microsomal and mitochondrial mem-

Table 2

Dietary fatty acid composition of marine and freshwater fishes ${ }^{\mathrm{a}}$

\begin{tabular}{|c|c|c|c|c|c|c|c|c|}
\hline \multirow[t]{2}{*}{ Species } & \multirow[t]{2}{*}{ Common name } & \multicolumn{7}{|c|}{ Fatty acids $(\mathrm{mol} \%)$} \\
\hline & & $18: 3 n-3$ & $18: 4 n-3$ & $20: \ln -9$ & $20: 5 n-3$ & $22: \ln -9$ & $22: 5 n-3$ & $22: 6 n-3$ \\
\hline Mallotus villosus & Capelin (female) & $\mathrm{nr}$ & $\mathrm{nr}$ & 17.2 & 8.6 & 14.2 & 0.9 & 4.8 \\
\hline Gadus morhua & Cod, Atlantic & 0.1 & 0.1 & 1.2 & 17.7 & 1.1 & 0.9 & 37.5 \\
\hline Prognichthys agoo & Flying fish (dorsal) & $\mathrm{nr}$ & $\mathrm{nr}$ & $\mathrm{nr}$ & 4.8 & $\mathrm{nr}$ & $\mathrm{nr}$ & 25.6 \\
\hline Meianogrammus & Haddock & 0.3 & $\mathrm{nr}$ & 3.5 & 14.3 & $\mathrm{nr}$ & 0.7 & 24.3 \\
\hline Hippoglossus hippoglossus & Halibut & $\mathrm{nr}$ & 1.4 & 7.3 & 12.6 & 5.0 & 2.3 & 19.2 \\
\hline Clupea harengus & Herring, Pacific & 0.6 & 2.8 & 9.4 & 8.6 & 11.6 & 1.3 & 7.6 \\
\hline Scomber scombrus & Mackerel & 1.3 & 3.4 & 3.1 & 7.1 & 2.8 & 1.2 & 10.8 \\
\hline Brevoortia tyrannus & Menhaden & 0.9 & 1.9 & 0.9 & 10.2 & 1.7 & 1.6 & 12.8 \\
\hline Mugil cephalus & Mullet, striped & 1.4 & 3.0 & 0.7 & 7.5 & 0.7 & 3.9 & 13.4 \\
\hline Sebastes marinus & Perch, ocean & 0.6 & 1.6 & 8.0 & 9.3 & 8.7 & 0.6 & 12.0 \\
\hline Sardinops sagax & Pilchards & 0.9 & 2.0 & 5.4 & 6.7 & 9.4 & 2.3 & 16.1 \\
\hline Oncorhynchus tshawytscha & Salmon, chinook & 0.9 & 1.5 & 4.7 & 8.2 & 3.6 & 2.4 & 5.9 \\
\hline Oncorhynchus keta & Salmon, chum & 1.0 & 2.0 & 5.4 & 6.7 & 9.4 & 2.3 & 16.1 \\
\hline Oncorhynchus gorbuscha & Salmon, pink & 1.1 & 2.9 & 4.0 & 13.5 & 3.5 & 3.1 & 18.9 \\
\hline $\mathrm{Nr}$ & Sardine & 1.3 & 2.9 & 8.1 & 9.6 & 7.8 & 2.8 & 8.5 \\
\hline Lateolabrax japonicus & Sea bass & $\mathrm{nr}$ & 2.6 & $\mathrm{nr}$ & 10.6 & $\mathrm{nr}$ & 1.8 & 21.8 \\
\hline Lamna cornubica & Shark, porbeagle & $\mathrm{nr}$ & $\mathrm{nr}$ & $\mathrm{nr}$ & 2.8 & $\mathrm{nr}$ & 13.7 & 29.0 \\
\hline Etelis evurus & Snapper & $\mathrm{nr}$ & $\mathrm{nr}$ & $\mathrm{nr}$ & 3.7 & $\mathrm{nr}$ & 1.4 & 33.8 \\
\hline Microstomus kitt & Sole, lemon & 2.0 & 1.6 & 3.9 & 11.9 & $\operatorname{tr}$ & 10.6 & 7.0 \\
\hline $\mathrm{Nr}$ & Swordfish & 0.4 & 0.7 & 4.6 & 4.4 & 2.0 & 3.1 & 17.8 \\
\hline Salmo gairdneri & Trout, rainbow & 5.2 & 1.5 & 3.0 & 5.0 & 1.3 & 2.6 & 19.0 \\
\hline Thunnus maccoii & Tuna, bluefin & $\operatorname{tr}$ & 0.9 & 0.3 & 6.4 & 5.4 & 1.4 & 17.1 \\
\hline Katsuwonus pelamis & Tuna, skipjack & 1.2 & 0.5 & 2.0 & 13.2 & $\operatorname{tr}$ & 1.5 & 17.3 \\
\hline Protothaca stiminea & Clam, littleneck & 1.6 & 3.0 & 3.5 & 10.0 & 2.6 & 1.7 & 14.5 \\
\hline Callinectes sapidus & Crab, blue & 1.2 & 0.6 & 1.9 & 13.4 & 1.5 & 1.1 & 11.0 \\
\hline Mytilus californianus & Mussel & $\mathrm{nr}$ & 1.6 & 2.6 & 14.0 & $\mathrm{nr}$ & 1.1 & 27.7 \\
\hline Crassostrea gigas & Oyster, Pacific & 1.6 & 4.3 & $\operatorname{tr}$ & 21.5 & 2.6 & 1.0 & 20.2 \\
\hline Placopecten magellanicus & Scallop, sea & 0.3 & 1.8 & 1.7 & 21.3 & 0.2 & 1.0 & 26.2 \\
\hline
\end{tabular}

\footnotetext{
a Abbreviations: 18:3n-3: alpha linolenic acid (LNA); 18:4n-3: stearidonic acid; 20:1n-9: eicosanoic acid; 20:5n-3: eicosapentanoic acid (EPA); 22:1n-9: 22:5n-3: docosapentaenoic acid (DPA); 22:6n-3: docosahexaenoic acid (DHA). Data taken from reviews by Gruger [48], and Salem [116].
} 


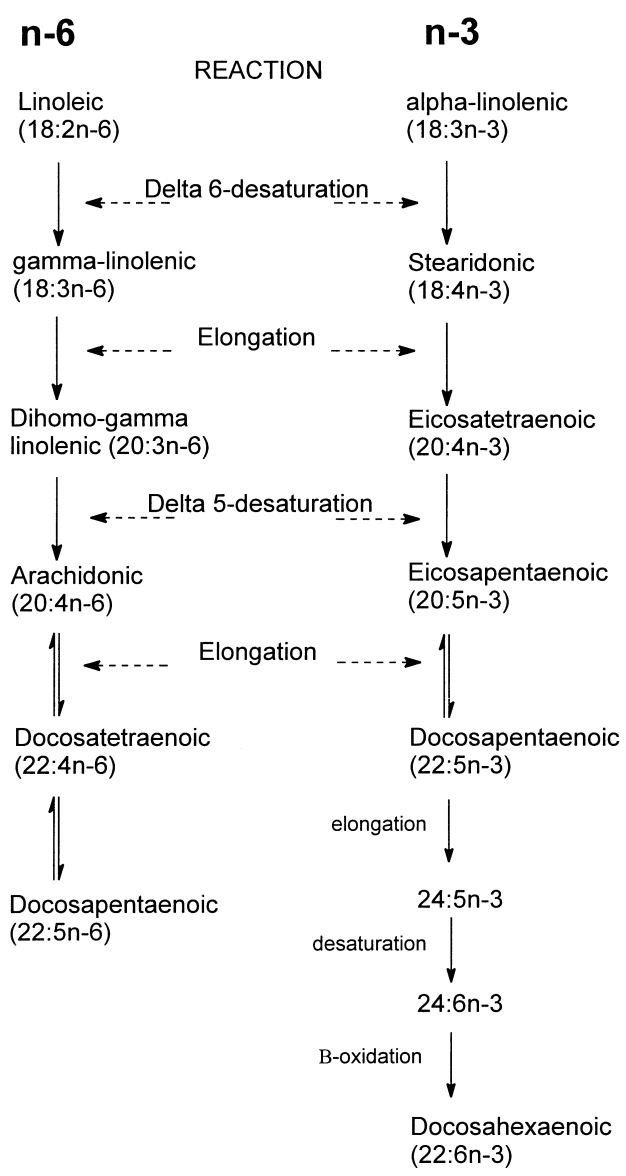

Fig. 1. Common pathways by which unsaturated fatty acids are converted to long-chain polyunsaturated fatty acids in animals. branes have also been reported [39,79,134,140]. In general, the developing brains of young animals can be modulated with dietary FAs supplemented over a short period of just a few weeks, as has been reported in mice [74], guinea pigs [155], and chicks [3]. With age, the modulation by dietary FAs on brain membrane FA composition takes longer, with most studies generally feeding older animals for at least 8 weeks $[17,84]$. However, in most of these studies, the exact time when changes in FA composition occurred, after supplementation began, is rarely investigated. Another factor to consider in comparing the time course required to change brain FA composition is the concentration of the supplement being used, which ranges from 5 to $20 \%$ of the diet.

Fish oils, which contain high levels of $\mathrm{C} 20$ and $\mathrm{C} 22$ PUFAs, exert the most profound influence on brain PUFA concentrations, in particular that of DHA (Table 2.). Interestingly the increase in DHA levels by dietary fish oils has a reciprocal effect on docosapentaenoic acid (DPA 22:5n-6) levels. In liver, diets rich in n-6 FAs would cause a significant increase in AA in response to DHA declines, yet in brain, AA concentrations are less influenced, and instead levels of DPA increase dramatically. This was shown by Neuringer and co-workers [91], who fed monkeys diets deficient in LNA throughout gestation and then to their infants during postnatal development. Animals fed diets deficient of n-3 displayed considerably less DHA in the cerebral cortex as compared with those fed a balanced diet, which was compensated by an increase in DPA concentrations. Anderson [3], reported similar compen-

Table 3

Dietary modulation of fatty acid composition in brain membranes ${ }^{\mathrm{a}}$

\begin{tabular}{|c|c|c|c|c|c|c|c|}
\hline \multirow[t]{2}{*}{ Diet } & \multirow[t]{2}{*}{ Tissue } & \multirow[t]{2}{*}{ Lipid class } & \multicolumn{4}{|c|}{ Fatty acids $(\mathrm{mol} \%)$} & \multirow[t]{2}{*}{ Reference } \\
\hline & & & $20: 4 n-6$ & $22: 5 n-6$ & $22: 5 n-3$ & $22: 6 n-3$ & \\
\hline Chow diet ad lib & RWB & TLE & 9.7 & 0.9 & $\mathrm{nr}$ & 12.3 & [58] \\
\hline Starved for two days & RWB & TLE & 9.8 & 0.9 & $\mathrm{nr}$ & 12.2 & [58] \\
\hline $10 \%$ Peanut oil & RWB & PE & 18.1 & 8.1 & - & 7.9 & [94] \\
\hline $10 \%$ Rapeseed oil & RWB & $\mathrm{PE}$ & 14.6 & 2.6 & - & 15.3 & [94] \\
\hline $18: 2 n-6+18: 3 n-3$ & RWB & PE & 11.8 & 1.0 & 0.3 & 23.7 & {$[136]$} \\
\hline $18: 2 \mathrm{n}-6$ only, & RWB & PE & 13.8 & 20.4 & 0.02 & 1.8 & {$[136]$} \\
\hline $8.5 \%$ Corn oil- $1.5 \%$ salmon oil & RWB & TLE & 9.1 & 0.4 & 0.2 & 12.3 & {$[17]$} \\
\hline $3 \%$ Corn oil- $7 \%$ salmon oil & RWB & TLE & 7.7 & 0.3 & 0.6 & 14.6 & {$[17]$} \\
\hline Palm oil (n-3 deficient) & RBSt & $\mathrm{PC}$ & 3.7 & $\mathrm{nr}$ & $\mathrm{nr}$ & 4.4 & {$[133]$} \\
\hline Sardine oil & RBSt & $\mathrm{PC}$ & 2.1 & $\mathrm{nr}$ & $\mathrm{nr}$ & 5.8 & {$[133]$} \\
\hline Palm oil (n-3 deficient) & RBSt & $\mathrm{PE}$ & 9.0 & $\mathrm{nr}$ & $\mathrm{nr}$ & 11.4 & {$[133]$} \\
\hline Sardine oil & RBSt & $\mathrm{PE}$ & 8.0 & $\mathrm{nr}$ & $\mathrm{nr}$ & 18.4 & {$[133]$} \\
\hline $8.04 \%$ Soybean oil ${ }^{\mathrm{b}}$ & CkWB & TLE & 10.7 & 3.7 & $\mathrm{nr}$ & 9.7 & [3] \\
\hline $7.41 \%$ Corn oil $^{\mathrm{b}}$ & CkWB & TLE & 10.5 & 8.3 & $\mathrm{nr}$ & 2.5 & [3] \\
\hline $7.41 \%$ Corn oil $+0.26 \% 22: 6 n 3^{b}$ & CkWB & TLE & 9.1 & 2.5 & $\mathrm{nr}$ & 12.8 & [3] \\
\hline
\end{tabular}

a Abbreviations: RWB: rat whole brain; RBSt: rat brain stem; CkWB: chick whole brain; TLE: total lipid extract; PE: phosphatidyl ethanolamine; PC: phosphatidyl choline; 20:4n-6: arachidonic acid (AA); 22:5n-6: docosapentaenoic acid (DPAn-6); 22:5n-3: docosapentaenoic acid (DPAn-3); 22:6n-3: docosahexaenoic acid (DHA).

${ }^{\mathrm{b}}$ Fat composition made up to $10 \%$ with hydrogenated coconut oil. 
satory increases in retinal and brain DPA content following the decline in DHA levels, in chicks fed diets containing corn oil, which has an n-6:n-3 ratio of 52 (Table 1). They also showed that this adjustment was reversed when corn oil was supplemented with DHAester. The results suggest that a high degree of unsaturation is required in brain, which appears to be best provided by DHA, but when dietary DHA is low, a compensatory increase in DPA levels occurs. The importance of DHA in brain tissue is further supported by several studies which have shown that a reduction of DHA concentrations following deprivation of n-3 FAs is reversible, with original concentrations obtained within a few weeks $[3,29,38]$. However, it would appear that declines in DHA levels through dietary deprivation of n-3 FA is more difficult in aged animals. This was shown by Bourre et al. [16], who found that adult rats fed a LNA deficient diet for 7 months did not exhibit declines in brain DHA levels, but instead significant declines were observed in other organs such as the liver and heart. These results further suggest the necessity to preserve brain DHA levels, though at the expense of other organs.

The information from these findings would suggest an essentiality for DHA in brain membranes, as it may play an important role in certain aspects of brain function $[25,64,69,99,133,159]$. One functional role may relate to its contribution in maintaining an appropriate state of membrane fluidity. Consequently, maintenance of an appropriate state of fluidity may modulate a number of aspects of lipid-protein interactions, including certain enzyme activities. It can also be degraded to EPA [151], a precursor for functionally important lipoxygenase products [30]. It is also worth noting that DHA, with its high degree of unsaturation, may be a vulnerable target to the damaging effects of lipid peroxidation. This raises the question that in such a delicate tissue such as the brain, evolution would have substituted DHA for a less vulnerable FA species if its presence was not essential for certain functions. Should DHA concentrations, not to mention that of other PUFAs, be altered in cell membranes, it is likely to have serious implications on the overall cellular function.

\section{Membrane structure and function: relation to fatty acid profile}

Inspite of the diversity in the types of cell membranes, they all compartmentalize the cell and provide domains in which very active enzymes, ions and transporters can be found. In general the lipid bilayer tends to exist at an optimum transition point between gel and liquid crystal, and the maintenance of this state, often loosely referred to as fluidity, is of paramount importance. The term "membrane fluidity" refers to the physical state of the fatty acyl chains comprising the membrane bilayer structure, as well as a measure of the different rates of motion of molecule elements within the membrane. The fatty acyl chains, which elicit the most influence, such as AA, EPA and DHA, contain double bonds, which are exclusively in the cis conformation. The replacement of even a single double bond in these PUFAs is sufficient to exert a profound effect on the physical properties of the membrane [28,82]. However, it cannot be taken as axiomatic that there is a simple linear relationship between the physical properties and the number of double bonds.

Many cellular functions and responses are thought to be affected, as a consequence of membrane lipid modification. However, it is important to realize that there are also inconsistencies with regard to this area, making it difficult to draw a general conclusion regarding functional changes in response to such modifications. Even if changes in fluidity parallel functional modifications, this may just be an ensuing effect, rather than a causative effect. Nevertheless, a wealth of studies have highlighted the important roles played by lipids. The exact mechanism whereby lipids can influence the properties of enzymes and transporters is still unclear. It is possible that the different lipids exert different effects on the fluidity of the membrane which result in the enhancement or loss of important associations between enzymes or transporters and the membrane, thus affecting the accessibility of their binding sites to their respective substrates. The subject of membrane transporters and enzyme activities is a very broad topic, however, some important activities associated with brain function, found to be affected by PUFAs are discussed below.

Membrane FA composition, which as discussed previously, can be modulated through dietary sources, provides the general framework that coordinates the fluidity of the membrane and consequently the efficiency of membrane systems. One particular membrane transporter whose activity is often assessed, is that of the $\mathrm{Na}^{+}, \mathrm{K}^{+}$ATPase. Viani [150] reported that age-related declines in PUFAs resulted in a decrease of $\mathrm{Na}^{+}$, $\mathrm{K}^{+}$ATPase activity in brain synaptosomes. However, Tsutsumi et al. [143], showed that rats fed high LA safflower oil did not exhibit significant changes in synaptosomal $\mathrm{Na}^{+}, \mathrm{K}^{+}$ATPase activity following the decline in DHA levels. They did however find, $\mathrm{Na}^{+}$, $\mathrm{K}^{+}$ATPase activity in myelin decreased together with 5 '-nucleotidase activity in the rat cortex and hippocampus. Polyunsaturated fatty acids have also been shown to regulate neuronal excitability [152]. Vreugdenhil et al. [152], showed that extracellular application of DHA or EPA to freshly isolated hippocampal CA1 neurons produced a concentrationdependant shift of the voltage dependence of inacti- 
vation of $\mathrm{Na}^{+}$and $\mathrm{Ca}^{2+}$ currents to more hyperpolarized potentials. This consequently accelerated the inactivation and retarded the recovery from inactivation, which may have potential anticonvulsive effects in vivo. With respect to enzymes important in cellular function, an important relationship between DHA and $\mathrm{PLA}_{2}$ has been reported $[59,80,120]$. Shikano et al. [120], found that following DHA supplementation into culture of human eosinophilic leukemia cells (Eol-1), platelet activating factor (PAF) production was reduced, whilst supplementation with EPA had no effect. It appeared that DHA attenuated $\mathrm{PLA}_{2}$ activity, though the exact mechanism was not known, consequently reducing the levels of AA liberated, a rate limiting step in the synthesis of biologically active eicosanoids. Martin [80], also found a correlation between DHA and $\mathrm{PLA}_{2}$ activity, a rate-limiting enzyme involved in the hydrolysis of AA from membranes for metabolism into eicosanoids. He showed that supplementation of PC12 cell media with DHA increased levels of this PUFA in ethanolamine glycerolipids of the neurite and nerve growth cone (NGC) fraction, which was accompanied by a concomitant decline in $\mathrm{PLA}_{2}$ activity, which may have important implications, when considering the role $\mathrm{PLA}_{2}$ plays in ischemia. The involvement of DHA in synaptic signal transduction has also been reported [59]. Jones and coworkers [59], demonstrated that following intravenous infusion of $\{4,5-3 \mathrm{H}\} \mathrm{DHA}$, that plasma $\{3 \mathrm{H}\} \mathrm{DHA}$ incorporation is selectively increased into synaptic membrane phospholipids of the rat brain in response to cholinergic activation. This indicates a primary role for DHA in phospholipid mediated signal transduction at the synapse involving activation of phospholipase $\mathrm{A}_{2}$ $\left(\mathrm{PLA}_{2}\right)$ and/or C. The potential role of PUFAs in signal transduction, was also reported by Slater et al. [125], who found using a model bilayer system, that alterations in the unsaturation of phosphatidyl choline (PC) phospholipids, elevated the activity of protein kinase $\mathrm{C}$ (PKC) alpha, possibly through changes in membrane surface curvature stress. By contrast, increasing the unsaturation of phosphatidyl serine (PS), decreased PKC alpha activity. The effects of PS unsaturation may be due to specific lipid-protein interactions. This result indicates that changes in phospholipid unsaturation may have profound effects on signal transduction pathways in which PKC plays a contributory role. Similar effects of PUFAs on PKC activity have also been reported by Goldberg and Zidovetzki [42].

These observations reported above are the some of the specific effects that PUFAs play on cellular activity, moreover, several behavioral aspects of brain function have also been shown to be affected by dietary FAs. For example, rats fed a safflower oil diet, which has a n-6:n-3 FA ratio greater than 75 (Table 1), through two generations exhibited significantly lower phospholipid levels of DHA, by as much as $90 \%$ compared with those fed a soybean oil diet which has a more balanced n-6:n-3 ratio of approximately 7 [69]. Presumably the high levels of LA in safflower oil down-regulated n-3 EFA desaturation, resulting in the loss of membrane n-3 PUFAs. Reflexes and motor abilities developed normally in both dietary groups, but deficient rats did exhibit fewer exploratory behaviors. They also performed more poorly in maze-learning tasks. More recent studies have also reported a correlation between changes in behavior and learning parameters with changes in brain membrane PUFAs composition [25,47,99,133]. Okuyama [99], reported that the general behavioral patterns in rats fed 5\% safflower oil containing $75 \%$ LA for two generations differed significantly from those in rats fed perilla oil, high in n-3 fatty acids (53\%). Brightness-discrimination, learning ability and retinal function were also higher in rats fed perilla oil compared with those fed safflower and also with those fed 5\% soybean oil $(53 \%$ n-6 and 4\% n-3). Greiner et al. [47], showed that following an n-3 deficient diet, rats performed poorer in olfactory-based and spatial learning tasks. Furthermore, Chalon [25] found that a fish oil complex $(50 \%$ salmon oil $+50 \%$ palm oil) enhanced neurochemical and behavioral variables in monoaminergic functions of rats, compared with those fed a combination of peanut and rapeseed oil, high in n-6 FAs. Changes in cerebral acetylcholine uptake, following dietary DHA supplementation has also been reported [87]. Docosahexaenoic acid was found to ameliorate impaired learning ability in stroke-prone spontaneously hypersensitive rats exhibiting cholinergic dysfunction [87].

The importance of n-3 PUFAs was also reported by Yamamato and co-workers [159], who found that rats fed LNA had a longer mean survival time and increased learning ability in senescence. It seems unlikely that these effects were due to LNA itself, as very little concentrations are retained in brain membranes, and to date no biological functions have been reported for this fatty acid, except as that of a precursor to n-3 PUFAs. The role of PUFAs in cognitive and behavioral functions in not just limited to rat models. In fact, Kalmijn [63], using data from the Zutphen elderly study found that in participants, n-3 PUFA consumption, primarily in the form of fish oil, tended to be inversely associated with cognitive impairment and cognitive decline. Additionally, the Zutphen elderly study raised the possibility that LA intake is positively associated with cognitive impairment.

So far, the discussion has focused on the importance of increasing concentrations of brain PUFAs, in particular that of DHA, through dietary manipulations, and the potential benefits that may transpire with respect to cellular functions, as well as brain functions 
such as memory, learning and behavior. However, it is important that the reader be aware of the importance of EFAs in the neurologic development of the embryonic brain. It has been suggested that the growing fetus obtains its supply of EFAs from its mother's EFA stores [146]. Thus, it would seem logical that if these stores are limited or not balanced with the correct PUFAs, there is the potential risk for structural aberrations, which may have deleterious effects on fetal and/or neonatal brain functions.

Production of neurons (neurogenesis) takes place over varying lengths of time, depending on the region of the nervous system and the neuron type [50]. Neurogenesis peaks around the 14th week of gestation and is completed by around the 25th week, once adult neuron numbers are attained [50]. Just prior to completion of neurogenesis, functional connections between target cells in the nervous system are established, through the growth of neurites (axons and dendrites) and the formation of synapses, known as synaptogenesis. This too, follows a cell and region specific timetable. Following neuron development, glial cells begin to originate (gliogenesis). Unlike neurons, glial cell production continues throughout adult life. The importance of DHA during these various developmental stages was shown by Green and co-workers who found that at the 17 th embryonic day the increase in rat brain PUFA concentrations plateaued, except that of DHA, which accumulated further [46]. This steep accumulation was found to occur just prior to synaptogenesis. Similar findings had previously been reported by Martin and Bazan [81], who found that both nerve growth cones and synaptosomes incorporated $\{3 \mathrm{H}\} \mathrm{DHA}$ during synaptogenesis in particular the phosphatidyl ethanolamine, serine and choline phospholipid classes, with a nominal amount found in the phosphatidyl inositol (PI) fraction. These findings in part suggest a necessity for DHA, and hence sufficient dietary consumption by the mother, that can be utilized by the developing fetus. Furthermore, reports have shown the importance of DHA during gliogenesis [55,56]. Ikemoto et al. [55,56], found using PC12 cells that DHA promotes neurite outgrowth, in contrast to AA which suppresses this process. They hypothesised that decreased phospholipid synthesis, in particular PE by arachidonic acid may lead to the suppression of neurite growth.

\section{Essential fatty acids as precursors of eicosanoids}

In addition to functioning as physical and chemical barriers separating aqueous compartments, membrane lipids as discussed earlier, are involved in many aspects of cell function and response. With the discovery that several classes of lipid have profound effects on cell function, particular attention is now directed at investigating the role(s) of specific FAs in different regulatory processes. When cells are activated by a variety of stimuli, their membrane lipids are rapidly remodelled to generate biologically active lipid mediators that can serve as intracellular or extracellular signals. The primary sources of these active lipid mediators are from the EFA families derived from LA and LNA. As previously described, FAs provide energy and are an integral part of the cell membrane, but some of the FAs are precursors for what have been defined as eicosanoids, which include: prostaglandins (PG), thromboxanes (TX), leukotrienes (LT), and the intermediate hydroperoxyeicosatetraenoic (HPETE) and hydroxyeicosatetraenoic (HETE) acids.

Both prostaglandins and leukotrienes act in a paracrine and autocrine form on cell function through a family of transmembrane receptors $[20,126]$ regulating numerous aspects of cell functions. In addition, experimental evidence supports the position that the eicosanoid compounds are also involved in a range of physiological and pathological processes, including vascular [93], immunological [44,52] and inflammatory [96] responses. Thus, EFAs are essential not only because they must be provided in the diet, as they can not be synthesised de novo, but also in part because of their physiological importance.

Interestingly, administration of distinct EFA precursors, influences, eicosanoid production, which can evoke opposing effects to potentiate or reduce inflammatory mediators [108]. In addition, numerous experimental and clinical studies have suggested that marine n-3 PUFAs such as EPA and DHA have significant benefits in preventing the development of atherosclerosis and lipoprotein metabolism [15,101,157]. For example, epidemiological evidence suggests that diets rich in DHA might protect against cardiovascular disease, by working at two levels: lowering plasma lipids and affecting eicosanoid biosynthesis [1,92]. Fish oils, as shown in Table 2, provide a rich source of PUFAs, especially EPA and DHA, which as discussed previously, have been found to increase membrane compositions of these respective PUFAs in various peripheral tissues $[8,19,74,88,89,95,100]$. Enrichment of the diet with EPA is followed by a concomitant enhancement in the activity of 5-lypoxygenase enzyme, because this FA is a preferred substrate for 5-lypoxygenase as compared with AA [97]. This is an important physiological event since the metabolism of EPA favors the synthesis of leukotriene $\mathrm{B}_{5}\left(\mathrm{LTB}_{5}\right)$ instead of $\mathrm{LTB}_{4}$ (Fig. 2). Consequently, the less active $\mathrm{LTB}_{5}$ as compared with $\mathrm{LTB}_{4}$ in chemotactic and aggregation activities will potentiate a more confined inflammatory response during an inflammatory-mediated insult. In addition, membrane EPA and DHA as modulated by dietary sources are also precursors of 
the 3-series of prostanoids and the 5-series of leukotrienes (Fig. 2), which have been shown to exhibit lesser aggregatory and inflammatory properties compared with the corresponding AA metabolites. Hence, this suggests that diets providing high concentrations of PUFAs (i.e., fish and fish oils) not only modulate membrane composition, providing a beneficial milieu for optimum membrane function (as has been shown in brain and retinal tissues), but also reduce synthesis of harmful eicosanoids derived from AA, the concentrations of which are lowered in compensation for the increase in membrane PUFAs provided by the diet. Suffice it to say, the opposite is seen with the consumption of diets high in n-6 FA which provide a source for AA synthesis.

Regardless of whether membrane AA concentrations are lowered by diets high in n-3 FA or increased by diets high in n-6 FA, the PUFA with the highest concentrations within membranes is most often than not AA [160]. This may in part explain the fact that AA is the most common substrate in humans for the synthesis of eicosanoids, which yield two series of prostaglandins, the 1 and 3 series. The synthesis of prostaglandins begins with the rate-determining hydrolysis of AA and other 20-carbon PUFAs from the sn2-position of the phospholipids [66,126]. Metabolites of AA are responsible for many of the manifestations of inflammation.

Arachidonic acid liberated from the phospholipids is a short-lived molecule that immediately becomes the substrate of heme-containing enzymes that add oxygen atoms to various positions in the chain, creating a variety of highly functional groups. Such changes transform the highly lipophilic AA into compounds of intermediate lipid:water solubility to allow better diffusion through water phases and cytoplasmic constituents. Consequently, the effect resulting from one of the oxidation steps is in the formation of a five- or six-carbon ring in the middle of the chain, increasing its rigidity as compared to its linear precursor. This enhanced rigidity is important in the binding of AA metabolites to corresponding receptors and thus for the cellular actions that they promote. Arachidonic acid metabolism is initiated either by cyclooxygenase, generating prostaglandins, thromboxanes, and prostacyclines, or by lipooxygenase to generate leukotrienes and lipoxins (Fig. 2).

\section{Cyclooxygenase-derived eicosanoids}

The cyclooxygenase-catalyzed addition of two mol-

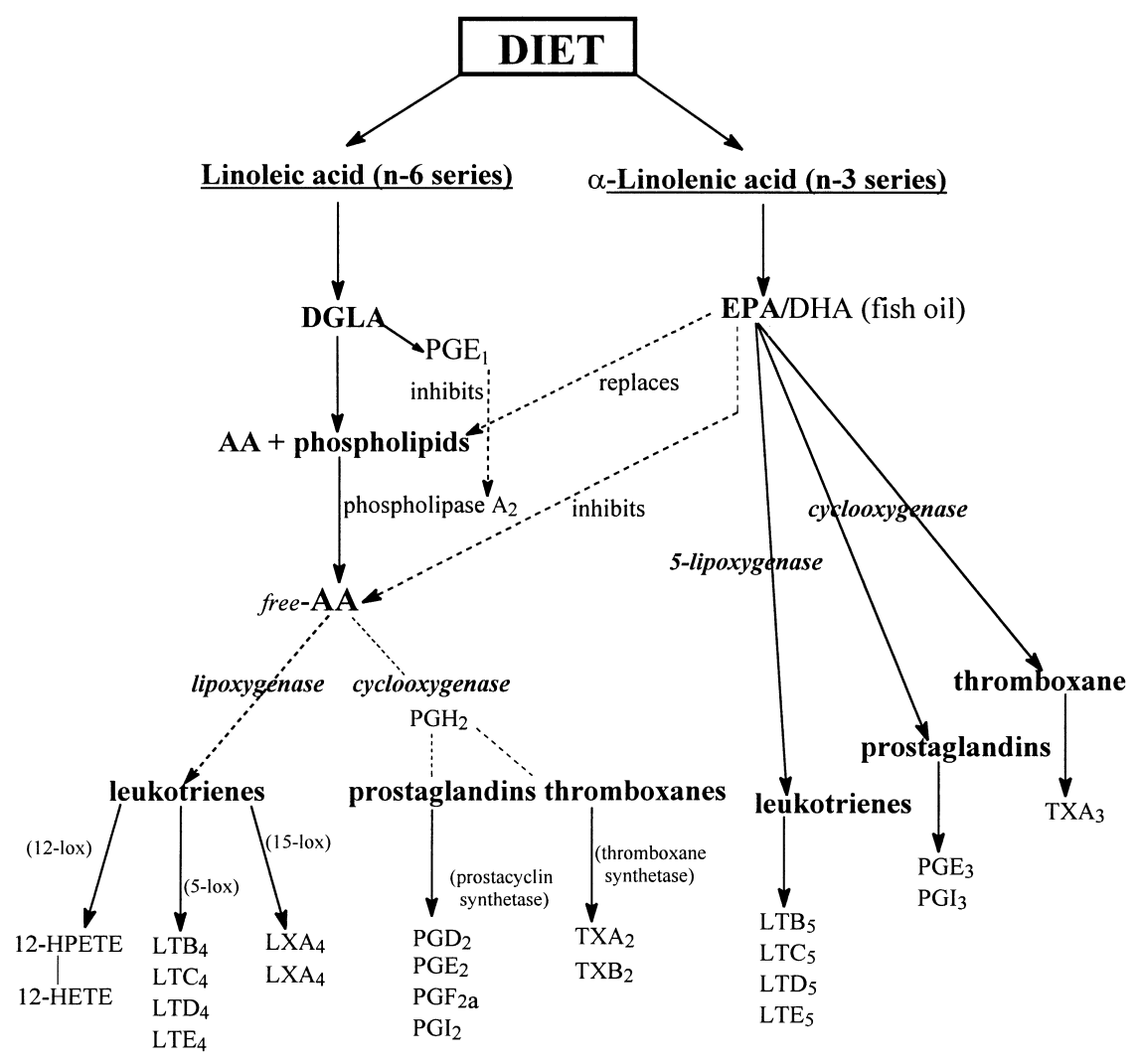

Fig. 2. Dietary fatty acids as precursors for eicosanoid synthesis. 
ecules of oxygen results in the synthesis of prostaglandins. The cyclooxygenase enzyme converts AA into cyclic endoperoxide, a key precursor molecule in the syntheses of prostacyclin $\left(\mathrm{PGI}_{2}\right)$ a potent vasodilator, thromboxane $\left(\mathrm{TXA}_{2}\right)$ a potent vasoconstrictor, and other prostaglandins $\left(\mathrm{PGE}_{2 \mathrm{a}}, \mathrm{PGF}_{2}\right.$ and $\left.\mathrm{PGD}_{2}\right)$ (Fig. 2). These aforementioned eicosanoids are synthesized from $\mathrm{PGH}_{2}$ an initial product of the action of cyclooxygenase on free arachidonic acid [119]. In some systems such as vascular endothelial cells and smooth muscle cells, $\mathrm{PGI}_{2}$ is perhaps the most important product. $\mathrm{PGI}_{2}$, synthesized by both endothelial and vascular smoother muscle cells, has opposite effects on platelets and vascular tone acting as a potent vasodilator and endogenous inhibitor of platelet aggregation. $\mathrm{TXA}_{2}$ is the predominant cyclooxygenase product in platelets and acts as a vasoconstrictor and promotor of platelet aggregation. In the case of cardiovascular disease, both $\mathrm{PGI}_{2}$ and $\mathrm{TXA}_{2}$ appear to play a very important role in the pathogenesis of vascular occlusive syndrome in humans [37]. $\mathrm{PGI}_{2}$ appears to play a local role at the platelet-vascular interface counteracting the TX-mediated effects on platelet aggregation. Different prospective clinical trials have demonstrated the efficacy of aspirin (a cyclooxygenase inhibitor) treatment in unstable angina [57]. Increased evidence has been accumulated for the role of TX as a mediator of patho-physiological processes and some human diseases. From clinical trials it seems that $\mathrm{TXA}_{2}$ has a functional importance in the pathogenesis of transient ischemic attacks and stroke [147]. Interestingly, a $\mathrm{TXA}_{2}$ receptor, which has been cloned from cultured rat astrocytes, is homologous with mouse and human $\mathrm{TXA}_{2}$ receptors at $92.7 \%$ and $71.8 \%$, respectively, and has shown ubiquitous expression in brain glial cells such as astrocytes, oligodendrocytes and microglia [66]. The selective conservation of the capability to synthesize specific eicosanoids such as $\mathrm{TXA}_{2}$ indicates that these cells have a characteristic AA metabolism and that these metabolites must play important roles in the brain. In addition, two distinct pools of phospholipases may subsist in the cell, a cytosolic (5-lipoxygenase) and a microsomal (cyclooxygenase) [10]. Interestingly, lipopolysaccharide stimulates the formation of $\mathrm{PGE}_{2}$ [107], while zymosan, a phagocytosable inflammatory mediator, stimulates the formation of $\mathrm{LTC}_{4}, \mathrm{LTB}_{4}$, and $\mathrm{PGE}_{4}$ [41].

\section{Lipoxygenase system}

The lipoxygenases are di-oxygenases that incorporate molecular oxygen into specific positions within PUFAs, and based on the site of insertion of the oxygen, are classified as 5-, 12-, or 15-lipoxygenases [121]. Lipoxygenases catalyze the addition of a single mol- ecule of oxygen converting AA to oxygenated products (leukotrienes) which posses potent biological properties. Lipoxygenase activity has been detected in platelets, leukocytes, lungs, skin, ocular tissue, and blood vessels [83]. In brain, 12-lipoxygenase has been found to be most prominent, expressed in cortical neurons, oligoendrocytes, and astrocytes [6]. The main metabolite produced by this enzyme is 12-HETE. It has been suggested, that these metabolites may play important roles as second messengers in synaptic transmission and intercept the learning and memory processes [105]. Interestingly, a significant association has been shown between the decrease of glutathione and the activation of 12-lipoxygenase, and its connection to $\mathrm{Ca}^{2+}$ influx and neural toxicity [110]. Its activity can be stimulated by chemical, mechanical, or immunological challenge, although it has been suggested that this enzyme is initially activated by glutathione depletion [72].

When AA is subject to oxidation via the 5-lipoxygenase enzyme the product is 5(S)-hydroperoxy6,8,11,14-eicostetraenoic acid (5-HPETE). Under appropriate stimulatory conditions, including the presence of $\mathrm{Ca}^{2+}$ and ATP, 5-lipoxygenase catalyzes two sequential reactions. The first involves the insertion of molecular oxygen at the carbon-5 position of AA to form 5-HPETE, followed by the metabolism of 5HPETE into unstable epoxides e.g., LTA 4 . Because these compounds are relatively unstable they are hydrated enzymatically to $\mathrm{LTB}_{4}$, or conjugated with glutathione to its metabolites leukotrienes $\mathrm{C}_{4}, \mathrm{D}_{4}$ and $\mathrm{E}_{4}$. The physiological effects of leukotrienes, involve, increased vascular permeability, enhanced contraction of smooth muscle cells in both large and smaller arteries, including coronaries vessels, dilatation of postcapillary venules, and enhanced mucous secretion [139]. These compounds also play important roles in immune response [115]. In both experimental animals and man, 5-lipoxygenase activity has been found to increase in anaphilactic and inflammatory processes. $\mathrm{LTB}_{4}$ is a potent activator of human neutrophils that enhances their adherence to the endothelial cells surface [83] an important early signal which mediates the migration of neutrophils to sites of inflammation (neutrophil chemotaxis). In addition, $\mathrm{LTC}_{4}-\mathrm{D}_{4}-\mathrm{E}_{4}$ increase vascular permeability and represent major inflammatory mediators secreted by mast cells, eosinophils, or basophils following antigen challenge [139]. Therefore, an understanding of the regulation of the 5-lipoxygenase, is important in future attempts to control these pathophysiological processes.

The initial events involved in accessing the precursor for the synthesis of eicosanoids such as those mentioned above, begin interestingly by the activation of receptors on the cell surface followed by G-protein coupled stimulation of phospholipase $\mathrm{C}$, an enzyme located on the internal surface of the plasma mem- 
brane. Phospholipase $\mathrm{C}$ catalyzes the hydrolysis of membrane bound phosphatidylinositol-2,4-biphosphate $\left(\mathrm{PIP}_{2}\right)$, resulting in the formation of 1,4,5-triphosphate $\left(\mathrm{IP}_{3}\right)$ and diacylglycerol (DAG). In addition, increased $\mathrm{Ca}^{2+}$ levels also activate $\mathrm{PLA}_{2}$, releasing AA from membrane phospholipids [9]. Leukotrienes, like prostaglandins, act through G-protein-coupled transmembrane receptors [20]. Although the distribution of 5lipoxygenase is restricted to certain myeloid cells, $\mathrm{LTB}_{4}$ is secreted by other cells because the enzymes capable of catalyzing the conversion of $\mathrm{LTB}_{4}$ to other leukotrienes are widely distributed in tissues $[10,20]$. In fact $\mathrm{LTB}_{4}$ has been identified in inflammatory exudates in arthritis [142] and cystic fibrosis [71] and in the epidermis of patients with psoriasis [141]. Leukotrienes $\mathrm{C}_{4}-\mathrm{D}_{4}-\mathrm{E}_{4}$ have also been identified in several models of inflammation, in particular, hypersensitivity disorders such as asthma [61]. Therefore, those agents or dietary interventions capable of reducing the synthesis of $\mathrm{LTB}_{4}$ will play an important role in reducing the inflammatory components that accompany various pathological processes.

\section{Essential fatty acids and aging}

The recognition of FA, as mediators of several physiological functions including the immune response is recent. Interest in the effects of FA, and the potential for therapeutic use, is a new concept. Modifications in prostaglandin synthesis induced by dietary FA has been shown with regard to saturated FAs, EFA deficiency; LA and LNA and n-3 PUFAs. Tissue concentrations of these PUFAs have been shown to decrease during aging $[160,161]$. Linoleic acid in particular, has been clearly shown to decrease in the elderly subjects while those of monounsaturated FAs increase [149]. These changes may have relevant physiological consequences upon health outcome and health related pathologies associated with aging.

One age-related factor influencing membrane PUFA composition, are the enzymes involved in their synthesis from dietary precursors, such as LA and LNA (Fig. 1). Studies have shown that in aging rodents, liver capacity to desaturate n-6 and n-3 FAs increased, while that of their brain decreased $[31,73,77]$. However, other studies have shown that in aged rodents, the desaturase capacity of the rat liver $[11,14,70]$ and mouse liver [18] decreases with age. Although there are a number of conflicting results reported, it is generally thought, that $\Delta 6$ and $\Delta 5$ desaturase activities decline during aging. Interestingly, dietary supplementation with EFAs can influence age-related changes in desaturase activity $[14,32,40,76]$. In this regard, with a decline in $\Delta 6$ desaturase activity, high consumption of LA and LNA would have a reduced impact on the synthesis of longer-chained PUFAs. However, the consumption of diets containing C20 and 22 PUFAs would avoid this limiting factor. Similar affects have also been shown with dietary supplementation of $\gamma$ LNA, often in the dietary form of evening primrose oil, which would by-pass the initial $\Delta 6$ desaturase step, and hence provide a source for n-6 PUFAs. This may be important, as $\gamma$ LNA increases the content of its elongase product DGLA within cell membranes without concomitant changes in AA [108]. Subsequently, upon stimulation, DGLA can be converted by inflammatory cells to 15-(S)-hydroxy-8,11,13-eicosatrienoic acid and $\mathrm{PGE}_{1}$. This is noteworthy, because both these compounds posses anti-inflammatory and antiproliferative properties $[35,108]$.

While changes in PUFA synthesis plays an important role, due attention must also be paid to the role played by oxidative stress (OS), which refers to the cytopathologic consequences of a mismatch between the production of reactive oxygen species (ROS) and the cells ability to defend itself against them. Numerous studies have been performed in this regard, which have shown an age-related increase in ROS and their deleterious effects on lipids, in particular their PUFA components. These age-related declines in peripheral tissue PUFAs compositions, have previously been shown [160,161]. The increase in lipid peroxidation alters membrane permeability as well as oxidation of structurally important proteins, consequently disrupting transmembrane ion movements and cellular metabolic processes $[82,137]$.

Brain synaptic function, has also been shown to be compromised, as a consequence of aging [145]. One particular feature observed was an increase in lipid peroxidation end-products which was reflected by the decline in membrane PUFAs such as DHA. Morphological and functional changes found to correlate with PUFA declines, included: swollen astrocytes, deformed nerve cell nuclei, reduced acetylcholine release and decreased membrane fluidity [145]. These detriments could however, be reduced with antioxidant pre-supplementation. In addition, oxidative damage to cellular membranes plays an important role in the pathobiology of both chronic and acute tissue injuries. In fact it has been hypothesised, that in various disease conditions such as diabetes, cystic fibrosis, kwashiorkor, multiple sclerosis and some other neurological disorders in which some form of oxidative stress is involved, tissue FA patterns are characteristic of EFA deficiency [49]. Essential fatty acids also appear to play important roles on cytotoxic and tumour cell drug resistance to a variety of tumour cells in vitro, as found with LA and EPA, which potentiate the cytotoxicity of the anti-cancer drug: vincristine. These results, coupled with the observation that various FAs can alter the activity of cell membrane bound enzymes such as $\mathrm{Na}^{+}$, 
$\mathrm{K}^{+}$-ATPase and 5'-nucleotidase [143,150], levels of various antioxidants [63], p53 expression and the concentrations of protein kinase C $[42,125]$, suggest that EFAs and their metabolites, may significantly influence tumour cell drug resistance and tumor development. However, the effect of EFAs on cellular response still remains to be fully characterized.

Growing data from experimental models and from autopsies of human brain, implicate oxidative stress in diseases such as: Parkinsons's disease (PD), Alzheimer's disease (AD), and amyotrophic lateral sclerosis (ALS) $[78,123]$. Increased lipid peroxidation in the substantia nigra is one manifestation that occurs in Parkinson patients, along with increased dopamine turnover, reduced glutathione levels, elevated iron levels [102]. Increased lipid peroxidation, has also been observed in those diagnosed with Alzheimer's. Prasad [106] showed, that the PE fraction of Alzheimer's diseased brains, in particular regions such as hippocampus, parahippocampal gryus and inferior parietal lobule exhibited significant declines in concentrations of in particular DHA, AA and stearic acid (18:0). Unfortunately, there is a paucity of studies that have reported the role of diet and these diseases. What the results indicate, is that the EFA components of brain membranes are targets for OS, which appears to participate in the onset of these diseases. It seems likely that this is a progressive accumulation of damage, not a sudden insult, as these neurodegenerative diseases are most prominent in the elderly. The question remains "can eating sufficient/appropriate amount of EFAs help against the onset of these diseases?". Cynics would argue that surely by consuming more dietary EFA that this will only accommodate ROS in their destructive roles. This may well be true, but results have shown that consumption of EFA does not potentiate the damage induced by ROS. Calviello [22] reported that low doses of EPA and DHA $(360 \mathrm{mg} / \mathrm{kg}$ body weight/day) substantially modified the membrane composition of these particular FAs, without increasing susceptibility to oxidative stress. Unfortunately, this study did not examine the FA composition of brain membranes, which would have responded well to this supplementation. This would have been a good marker to test oxidative stress, since brain tissue has a low antioxidant status compared with other peripheral tissues [160,161]. Venkatraman [148] showed that in rat liver, following consumption of a $10 \%$ fish oil diet, there were significant increases in antioxidant defenses as compared with those receiving corn oil diet. Similar findings using Swiss 3T3 fibroblasts were reported by Benito and co-workers [7]. They found that enrichment of media with $5.6 \%$ EPA significantly increased superoxide dismutase, glutathione peroxidase and transferase activities compared with media that had been supplemented with LA.
It is interesting to note, that a number of other studies have shown negative effects related to LA supplementation, particularly its relationship with cytokines. It has been known for several years that CNS damage by infection, trauma, toxic agents, or oxidative stress usually leads to the formation of increased amounts of injury mediators such as Tumor Necrosis Factor $(\mathrm{TNF} \alpha)$ and/or interleukine-1 $\beta$ (IL$1 \beta$ ) [158]. Increased levels of these two cytokines, are linked to numerous degenerative diseases, including neurological disorders. These inflammatory disorders are complex and involve the activation of different genes, and the expression a large array of proteins with distinct activity involved in the molecular and cellular inflammatory responses [113]. Interestingly, an increased production of proinflammatory cytokines in the absence of the inflammatory stimulus is a frequent phenomenon that occurs in the elderly [85]. In conjunction with this observation, it has also been reported that $\mathrm{TNF} \alpha$ is produced in higher amounts during cytotoxic reactions in the elderly [26]. Even though the CNS cytokines play crucial roles in regulating the immune response to foreign antigens (infections), and in developing cellular and humoral immunity and inflammatory responses in brain, their toxic effects may be detrimental. In fact, an association has been demonstrated between cytokines and the production of oxygen species, changes in cell membrane composition, regulation of adhesion molecules, and apoptosis [90]. Toberek [138] found that LA may influence cytokine mediated cell dysfunction including $\mathrm{TNF} \alpha$ induced apoptosis. Although this study investigated this action in endothelial cells, it seems feasible that this may also be a physiological occurrence within brain cells. Such disruption may explain in part, the observed cognitive impairment in the participants of the Zutphen study consuming high LA. Other detrimental affects associated with LA have also been reported. Increased OS as measured by urinary excretion of 8-iso $\mathrm{PGF}_{2 \mathrm{a}}$, a product of a free radical catalyzed reaction, was found following dietary supplementation with $11.5 \%$ LA [144]. Adverse affects associated with Parkinson's have also been linked with LA. Pezzella [104], found that exposure of dopamine, which is known to have an increased turnover as characteristic of this disease, to an excess of LA in the presence of ferrous irons, potentiates the production of the neurotoxin quinone of 6-hydroxydopamine. The involvement of AA derived products, have been shown to be involved in the production and functions of cytokines, thus, it has been proposed that dietary effects on eicosanoid production could have important effects on cytokine production $[27,98]$.

It is important that the reader also be aware of the roles played by EFAs in ischemic brain injury. Over recent years, knowledge about the mechanisms of 
ischemic brain damage has increased considerably. Onset of cerebral ischemia results in a series of changes in brain metabolism, which eventually leads to declines in/loss of neuronal function. Alterations in membrane integrity during an ischemic insult can be attributed to phospholipid degradation. This may as a consequence of increased activation of phospholipases during an ischemic condition [112], and increased free radical reactions on membranes [154]. This degradation of membrane phospholipids leads to an increased level of free fatty acids. Furthermore, AA liberated from the membrane and its metabolites, has been shown to be the major contributor of disturbances in membrane functions, for example, declines in mitochondrial respiratory function [51,132] and ion transport systems [109].

As mentioned earlier, the generation of AA metabolites by cyclo-oxygenase and lipoxygenase requires oxygen, such that their production occurs predominantly during reperfusion. With these factors borne in mind, numerous studies have investigated how dietary EFAs may be able to ameliorate some of the deleterious symptoms associated with ischemia/reperfusion. This has been shown, following dietary supplementation with; ethyl docosahexaenoate [43], ethyl eicosapentate [65] and fish oils [68,86]. Thus, limiting the amount membrane AA, through manipulation by dietary n-6 FAs such as DHA or EPA will inevitably reduce the amount of free AA generated during ischemia/reperfusion and consequently less AA metabolites. In addition, it was reported earlier, that the activity of $\mathrm{PLA}_{2}$, a rate limiting step in the release of AA from membrane phospholipid could be reduced by dietary DHA, which too can reduce the availability of free AA for metabolism into various eicosanoids $[59,80]$.

A vast amount of work still remains to be investigated, regarding these observations before any general conclusions can be made. What these studies continue to show, are the diverse roles played by PUFAs and how members from different families exhibit/manifest different cellular functions/responses. Nonetheless, the findings that an optimum DHA milieu is important in various cognitive, behavioral and memory functions would suggest an important role for these PUFAs, and that this enhancement may preclude/delay the onset of neurodegenerative diseases. This is not to say that it will prevent their onset. The age-related decline in PUFAs may also play a part, in the detrimental roles that appear to be related to LA. A decline in the synthesis of PUFA from dietary LA will ultimately result in the increase incorporation of this FA into cell membranes. Likewise, cell membrane concentrations of this FA will also increase as a percentage of total FA, as PUFA concentrations decline from increased insult by ROS.

\section{Conclusions}

As early as 1929, Burr and Burr reported the essentiality for linoleic and linolenic acid in the human diet. Aptly these fatty acids became to be referred to as "essential fatty acids" and with time, and increasing knowledge, so did their various desaturated and elongated derivatives (Fig. 1). A vast amount of literature has shown the effects of modulating membrane FA composition on the functional efficacy of certain membrane associated enzymes as well as the functional roles of the whole tissue i.e. brain. Change in the membranes' fluidity appears to have the greatest influence on functional role played by certain enzymes. A tight control of FA interactions and their hydrophobic associations with proteins, as well as their influence on protein-protein interactions, contributes to attaining an appropriate state of fluidity, for the cell to perform its normal functions. These associations, have been shown to be altered by dietary consumption of different FAs. Two families, n-6 and n-3 exert the most influence, the content in membranes often reflecting the predominant dietary source.

Dietary sources that are bias to one FA family, often predispose cell membranes to those FAs. In general, the results observed from the studies reviewed here would indicate to the reader that maintaining an appropriate membrane EFA status is extremely important, in so far as cell functions. Those EFAs that appear to have more biological importance are members of the n-6 family in particular DHA. Maintaining concentrations of this PUFA, is likely to favor enhanced cognitive, learning and memory functions. It would appear that neurodegenerative disorders, such as $\mathrm{PD}$ and $\mathrm{AD}$ for example, often exhibit significant declines in this and other PUFAs, which may in part, contribute to some of the observed declines in brain functions. Eating a diet that would supply/maintain concentrations of these PUFAs, may help to delay the changes associated with diseases. The problem facing those already exhibiting clinical signs of these diseases is that a simple dietary regime may not be sufficient to reverse the process. It may be that a nutritional supplement of PUFAs is required, not to retard the disease but possibly help maintain the status quo of the individuals' general mental health. Unfortunately this may have certain drawbacks, especially when one raises the question of OS and the increase in lipid peroxidation of the PUFA components of cell membranes. The solution would therefore be, to provide in addition to essential PUFAs (without compromising their beneficial effects), antioxidant supplements such as vitamin E. In accordance with this, results from our lab have shown that consumption of fruit and vegetables rich in antioxidant flavanoids may contribute 
against the deleterious affects associated with ROS damage to brain function $[12,60,122]$. These and other types of antioxidant supplementation with an appropriate proportion of n-3 FA are the principle dietary components one should consume to help protect against insults associated with aging.

\section{References}

[1] Adan, Y., Shibata, K., Sato, M., Ikeda, I. and Imaizumi, K., Effects of docosahexaenoic and eicosapentaenoic acid on lipid metabolism, eicosanoid production, platelet aggregation and atherosclerosis in hypercholesterolemic rats. Biosci. Biotechnol. Biochem., 1999, 63(1), 111-119.

[2] Allison, D. B., Egan, S. K., Barraj, L. M., Caughman, C., Infante, M. and Heimbach, J. T., Estimated intakes of trans fatty acids and other fatty acids in the US population. J. Am. Dietetic Assoc., 1999, 99(2), 166-174.

[3] Anderson, G. J. and Connor, W. E., Accretion of n-3 fatty acids in the brain and retina of chick fed a low linolenic acid diet supplemented with docosahexaenoic acid. Am. J. Clin. Nutr., 1994, 59(6), 1338-1346.

[4] Andreassi, M., Forleo, P., Di Lorio, A., Masci, S., Abate, G. and Amerio, P., Efficacy of gamma-linolenic acid in the treatment of patients with atopic dermatitis. J. Int. Med. Res., 1997, 25(5), 266-274.

[5] Bazan, N. G., The metabolism of omega-3 polyunsaturated fatty acids in the eye: the possible role of docosahexaenoic acid and docosanoids in retinal physiology and ocular pathology. Prog. Clin. Biol. Res., 1989, 312, 95-112.

[6] Bendani, M., Palluy, O., Cook-Moreau, J., Beneytout, J., Rigaud, M. and Vallat, J., Localization of 12-lipoxygenase mRNA in cultured oligodendrocytes and astrocytes by in situ reverse transcriptase and polymerase chain reaction. Neurosci. Letters, 1995, 189(3), 159-162.

[7] Benito, S., Fernadez, Y., Mitjavila, S., Moussa, M., Anglade, F. and Periquet, A., Phospholipid fatty acid composition affects enzymatic antioxidant defences in cultured Swiss 3T3 fibroblasts. Redox Rep., 1997, 3, 281-286.

[8] Berlin, E., Bhathena, S. J., McClure, D. and Peters, R. C., Dietary menhaden and corn oils and the red blood cell membrane lipid composition and fluidity in hyper- and normocholesterolemic minature swine. J. Nutr., 1998, 128(9), 1421-1429.

[9] Berridge, M. J., Inositol trisphosphate and calcium signaling. Nature, 1993, 361, 315-325.

[10] Bhatia, P., Brooks, C., Basha, A., Ratajczyk, J., Gunn, B., Bouska, J., Lanni, C., Young, P., Bell, R. and Carter, G., 5Lipoxygenase inhibitors: synthesis and structure-activity relationships of a series of 1-aryl-2H,4H-tetrahydro-1,2,4-triazin3-ones. J. Medic. Chem., 1996, 39(20), 3938-3950.

[11] Biagi, P. L., Bordoni, A., Herlia, S., Celadon, M. and Horrobin, D. F., a-Linolenic acid dietary supplementation can reverse the aging influence on rat liver microsome delta- 6 desaturase activity. Biochim. Biophys. Acta, 1991, 1083, 187-192.

[12] Bickford, P. C., Shukitt-hale, B., Gould, T. J., Breidrick, L., Denisova, N., Bielinkski, D. and Joseph, J. A., Reversal of age-related declines in CNS neurotransmission with diets supplemented with fruit or vegatable extracts. In Society For Neuroscience, 1998 Los Angeles, Calif.

[13] Bjerve, K. S., Omega 3 fatty acid deficiency in man: implications for the requirement of alpha-linolenic acid and longchain omega 3 fatty acids. World Rev. Nutr. Dietetics, 1991, 66(66), 133-142.

[14] Blond, J. P. and Bezard, J., D5 desaturation of dihomogam- malinoleic acid (20:3(n-6)) into arachidonic acid (20:4(n-6)) by rat liver microsomes and incorporation of fatty acids in microsome phospholipids. Biochim. Biophys. Acta, 1991, 1084, 255260.

[15] Bordoni, A., Lopez-Jimenez, J. A., Spano, C., Biagi, P., Horrobin, D. F. and Hrelia, S., Metabolism of linoleic acid and alpha-linolenic acid in cultures cardiomyocytes: effect of different N-6 and N-3 fatty aid supplementation. Mol. Cell Biochem., 1996, 157, 217-222.

[16] Bourre, J. M., Dumont, O. S., Piciotti, M. J., Pascal, G. A. and Durand, G. A., Dietary alpha-linolenic acid deficiency in adult rats for 7 months does not alter brain docosahexaenoic acid content, in contrast to liver, heart and testes. Biochim. Biophys. Acta, 1992, 1124(2), 119-122.

[17] Bourre, J. M., Nonneil, M., Dumont, O., Piciotti, M., Claaf, R., Portugal, H., Nalbone, G. and Lafont, H., Effect of increasing amounts of dietary fish oil on brain and liver fatty acid composition. Biochim. Biophys. Acta, 1990, 1043, 149152.

[18] Bourre, J. M., Piciotti, M. and Dumont, O., Delta 6 desaturase in brain and liver during development and aging. Lipids, 1990, 25(6), 354-356.

[19] Bourre, J. M., Picotti, M., Dumont, O., Pascal, G. and Durand, G., Dietary linoleic acid and polyunsaturated fatty acids in rat brain and other organs. Minimal requirements of linoleic acid. Lipids, 1990, 25, 465-472.

[20] Brooks, C. and Summers, J., Modulators of leukotriene biosynthesis and receptor activation. J. Medic. Chem., 1996, 39(14), 2629-2654.

[21] Burr, G. O. and Burr, M. M., A new deficiency disease produced by the rigid exclusion of fat from the diet. J. Biol. Chem., 1929, 82, 345-367.

[22] Calviello, G., Palozza, P., Franceschelli, P. and Bartoli, G. M., Low-dose eicosapentaenoic or docosahexaenoic acid administration modifies fatty acid composition and does not affect susceptibility to oxidative stress in rat erythrocytes and tissues. Lipids, 1997, 32, 1075-1083.

[23] Carlier, H., Bernard, A. and Caselli, C., Digestion and absorption of polyunsaturated fatty acids. Reprod. Nutr. Devel., 1991, 31, 475-500.

[24] Cerolini, S., Kelso, K. A., Noble, R. C., Speake, B. K., Pizzi, F. and Cavalchini, L. G., Relationship between spermatozoan lipid composition and fertility during aging of chickens. Biol. Reprod., 1997, 57(5), 976-980.

[25] Chalon, S., Delion-Vancassel, S., Belzung, C., Guilloteau, D., Leguisquet, A. M., Besnard, J. C. and Durand, G., Dietary fish oil affects monoaminergic neurotransmission and behavior in rats. J. Nutr., 1998, 128(12), 2512-2519.

[26] Chang, H. N., Wang, S. R., Chiang, S. C., Teng, W. J., Chen, M. L., Tsai, J. J., Huang, D. F., Lin, H. Y. and Tsai, Y. Y., The relationship of aging to endotoxin shock and to production of TNFa. J. Gerontol., 1996, 51, M220-M222.

[27] Chavali, S. R., Zhong, W. W. and Forse, R. A., Dietary alpha-linolenic acid increases TNF-alpha, and decreases IL-6, IL-10 in response to LPS: effects of sesamin on the delta-5desaturation of omega 6 and omega 3 fatty acids in mice. Prostaglan. Leukotri. Essen. Fatty Acids, 1998, 58(3), 185-191.

[28] Cohen, B. M. and Zubenko, G. S., Aging and the biophysical properties of cell membranes. Life Sci., 1985, 37, 1403-1409.

[29] Connor, W. E., Neuringer, M. and Lin, D. S., Dietary effects on brain fatty acid composition: the reversibility of n-3 fatty acid deficiency and turnover of docosahexaenoic acid in the brain, erythrocytes, and plasma of rhesus monkey. J. Lipid Res., 1990, 31(2), 237-247.

[30] Conquer, J. A. and Holub, B. J., Dietary docosahexaenoic acid as a source of eicosapentaenoic acid in vegetarians and omnivores. Lipids, 1997, 32(3), 341-345. 
[31] Cook, H. W., Brain metabolism of a-linoleic acid during development. Nutrition., 1991, 7, 440-442.

[32] De Gomez, Dumm I. N. T., Alaniz, M. J. T. and Brenner, R. R., Effect of dietary fatty acids on delta- 5 desaturase activity and biosynthesis of arachidonic acid in rat liver microsomes. Lipids, 1983, 18(11), 781-788.

[33] Ehringer, W., Belcher, D., Wassall, S. R. and Stillwell, W., A comparison of the effects of linolenic (18:3 omega 3 ) and docosahexaenoic (22:6 omega 3) acids on phospholipid bilayers. Chem. Phys. Lipids, 1990, 54(2), 79-88.

[34] Ernst, N. D. In Health Effects of Dietary Fatty Acids, ed. G. J. Nelson. Am. Oil Chemists Soc, 1991, pp. 1-11.

[35] Fan, Y. Y. and Chapkin, R. S., Importance of dietary gamma-linolenic acid in human health and nutrition. J. Nutr., 1998, 128(9), 1411-1414.

[36] Fernstrom, J. D., Effects of dietary polyunsaturated fatty acids on neuronal function. Lipids, 1999, 34(2), 161-169.

[37] Fessatidis, I. T., Brannan, J. J., Taylor, K. M., KanellakiKyparissi, M., Abdulla, A. K. and Olsen, E. C., Effect of prostacyclin PGI2 on cardiopulmonary bypass-induced lung injury. Perfusion, 1994, 9(1), 23-33.

[38] Galli, C., Trzeciak, H. I. and Paoletti, R., Effects of dietary fatty acids on the fatty acid composition of brain ethanolamine phosphoglyceride: Reciprocal replacement of n-6 and n-3 polyunsaturated fatty acids. Biochim. Biophys. Acta, 1971, 248, 449-458.

[39] Galli, C., Trzeciak, H. I. and Paoletti, R., Effect of essential fatty acids deficiency on myelin and various subcellular structures in rat brain. J. Neurochem., 1972, 19, 1863-1867.

[40] Garg, M. L., Sebokova, E., Thomson, A. B. R. and Clandinin, M. T., Delta 6 desaturase activity in liver microsomes of rats fed diets enriched with cholesterol and/or $\omega 3$ fatty acids. Biochem. J., 1988, 249, 351-356.

[41] Gibbs, B. F., Schmutzler, W., Vollrath, I. B., Brosthardt, P., Braam, U., Wolff, H. H. and Zwadlo-Klarwasser, G., Ambroxol inhibits the release of histamine, leukotrienes and cytokines from human leukocytes and mast cells. Inflamm. Res., 1999, 48(2), 86-93.

[42] Goldberg, E. M. and Zidovetzki, R., Effects of dipalmitoylglycerol and fatty acids on membrane structure and protein kinase C activity. Biophys. J., 1997, 73(5), 2603-2614.

[43] Golzman, S., Green, P. and Yavin, E., Intraamniotic ethyl docosahexaenoate administration protects fetal rat brain from ischemic stress. J. Neurochem., 1998, 70(6), 2484-2491.

[44] Goodwin, J. and Ceuppens, J., The regulation of immune responses by prostaglandins. J. Clin. Immunol., 1983, 3, 295-308.

[45] Goustard-Langelier, B., Guesnet, P., Durand, G., Antoine, J. M. and Alessandri, J. M., N-3 and n-6 fatty acid enrichment by dietary fish oil and phospholipid sources in brain cortical areas and nonneuronal tissues of formula-fed piglets. Lipids, 1999, 34(1), 5-16.

[46] Green, P., Glozman, S., Kamensky, B. and Yavin, E., Developmental changes in rat brain membrane lipids and fatty acids. The preferential prenatal accumulation of docosahexaenoic acid. J. Lipid Res., 1999, 40(5), 960-966.

[47] Greiner, R. S., Moriguchi, T., Hutton, A., Slotnick, B. M. and Salem, N. J., Rats with low levels of brain docosahexaenoic acid show impaired performance in olfactory-based and spatial learning tasks. Lipids, 1999, 34, S229-S233.

[48] Gruger, E. H. J. In Fish Oils, Technology, Stability, Nutritional Properties, and Uses, ed. M. E. Stansby. Avi Publishing Co, Westport, 1967, pp. 3-30.

[49] Gutteridge, J. M., Quinlan, G. J. and Yamamoto, Y., Hypothesis: are fatty acid patterns characteristic of essential fatty acid deficiency indicative of oxidative stress. Free Rad. Res., 1998, 28, 109-114.

[50] Hartenstein, V., Early neurogenesis in Xenopus: The spatio- temperal pattern of proliferation and cell lineages in the embryonic spinal cord. Neuron, 1989, 3, 399-411.

[51] Hillered, L. and Chan, P. H., Role of arachidonic acid and other free fatty acids in mitochondrial dysfunction in brain ischemia. J. Neurosci. Res., 1988, 20(4), 451-456.

[52] Hirokawa, K., Utsuyama, M., Kasai, M. and Kurashima, C., Aging and immunity. Acta Pathologica Japonica, 1992, 42(8), 537-548.

[53] Hwang, D. In Fatty Acids in Foods and their Health Implications, ed. C. Chow. Marcel Dekker Inc, New York, 1992, pp. 545-557.

[54] Ikeda, I., Mitsui, K. and Imaizumi, K., Effect of dietary linoleic, alpha-linolenic and arachidonic acids on lipid metabolism, tissue fatty acid composition and eicosanoid production in rats. J. Nutr. Sci. Vitaminol., 1996, 42(6), 541-551.

[55] Ikemoto, A., Kobayashi, T., Emoto, K., Umeda, M., Watanabe, S. and Okuyama, H., Effects of docoshexaenoic and arachidonic acids on the synthesis and distribution of aminophospholipids during neuronal differetiation in PC12 cells. Arch. Biochem. Biophys., 1999, 364(1), 67-74.

[56] Ikemoto, A., Kobayashi, T., Watanabe, S. and Okuyama, H., Membrane fatty acid modifications of PC12 cells by arachidonate or docosahexaenoate affect neurite out growth but not norepinephrine release. Neurochem. Res., 1997, 22(6), 671-678.

[57] Ikonomidis, I., Andreotti, F., Economou, E., Stefanadis, C., Toutouzas, P. and Nihoyannopoulos, P., Increased proinflammatory cytokines in patients with chronic stable angina and their reduction by aspirin. Circulation, 1999, 100(8), 793-798.

[58] Joel, C. D., Ellis, C. A., Lace, J. K. and Joel, J. B., Stability of the brain fatty acid pattern in adult rats during extreme starvation. J. Neurochem., 1974, 23, 23-30.

[59] Jones, C. R., Arai, T. and Rapoport, S. I., Evidence for the involvement of docosahexaenoic acid in cholinergic stimulated signal transduction at the synapse. Neurochem. Res., 1997, 22(6), 663-670.

[60] Joseph, J. A., Shikitt-Hale, B., Denisova, N. A., Prior, R. L., Cao, G., Martin, A., Taglialatela, G. and Bickford, P. C., Long-term dietary strawberry, spinach, or vitamin E supplementation retards the onset of age-related neuronal signaltransduction and cognitive behavioral deficits. J. Neurosci., 1998, 18, 8047-8055.

[61] Juergens, U. R., Stober, M. and Vetter, H., Reproterol - A monomolecular combination of orciprenaline and theophylline: novel aspects of its mode of action in asthma. Respiration, 1999, 66(3), 220-224.

[62] Jumpsen, J., Lien, E. L., Goh, Y. K. and Clandinin, M. T., Small changes of dietary (n-6) and (n-3)/fatty acid concentration alter phosphatidylethanolamine and phosphatidylcholine fatty acid composition during development of neuronal and glial cells in rats. J. Nutr., 1997, 127(5), 724-731.

[63] Kalmijn, S., Feskens, E. J., Laurner, L. J. and Kromhout, D., Polyunsaturated fatty acids, antioxidants, and cognitive function in very old men. Am. J. Epidemiol., 1997, 145, 33-41.

[64] Kaplan, R. J. and Greenwood, C. E., Dietary saturated fatty acids and brain function. Neurochem. Res., 1998, 23(5), 615626.

[65] Katsumata, T., Katayama, Y., Obo, R., Muramatsu, H., Ohtori, T. and Terashi, A., Delayed administration of ethyl eicosapentate improves local cerebral blood flow and metabolism without affecting infarct volumes in the rat focal ischemic model. Eur. J. Pharmacol., 1999, 372(2), 167-174.

[66] Kitanaka, J., Hashimoto, H., Sugimoto, Y., Sawada, M., Negishi, M. and Suzumura, A., cDNA cloning of a thromboxane A2 receptor from rat astrocytes. Biochim. Biophys. Acta, 1995, 1265(23), 220-223.

[67] Kromhout, D., de Lezenne C, Coulander, Obermann-de, Boer G. L., van Kampen-Donker, M., Goddijn, E. and Bloemberg, 
B. P., Changes in food and nutrient intake in middle-aged men from 1960 to 1985 (the Zutphen Study). Am. J. Clin. Nutr., 1990, 51(1), 123-129.

[68] Lai, M. L., Hsu, C. Y., Lui, T. H., He, Y. Y., Xu, J., Navidi, M., Sun, G. and Hogan, E. L., Effects of fish oil supplementation on acute ischemic brain injury in the rat. Neurology, 1993, 43(6), 1227-1232.

[69] Lamptey, M. S. and Walker, B. L., A possible dietary role for linolenic acid in the development of the young rat. J. Nutr., 1976, 106, 86-93.

[70] Langaniere, S., Modulation of membrane phospholipid fatty acid composition by age and food restriction. Gerontol., 1993, 39(1), 7-18.

[71] Lawrence, R. H. and Sorrell, T. C., Eicosapentaenoic acid modulates neutrophil leukotriene B4 receptor expression in cystic fibrosis. Clin. Exp. Immunol., 1994, 98(1), 12-16.

[72] Li, Y., Maher, P. and Schubert, D., A role for 12-lipoxygenase in nerve cell death caused by glutathione depletion. Neuron, 1997, 19, 453-463.

[73] Lopez, G. H., Ilincheta de Boschero, M. G., Castagnet, P. I. and Giusto, N. M., Age associated changes in the content and fatty acid composition of brain glycerophospholipids. Compara. Biochem. Physiol., 1995, 112(2), 331-343.

[74] Lui, Y. and Longmore, R. B., Dietary sandalwood seed oil modifies fatty acid composition of mouse adipose tissue, brain and liver. Lipids, 1997, 32(9), 965-969.

[75] MacDonald, R. S., Zhang, W., Zhang, J. P. and Sun, G. Y., Brain neutral lipids and phospholipids are modified by longterm feeding of beef tallow vs corn oil diets. J. Nutr., 1996, 126(6), 1554-1562.

[76] Mahfouz, M. M., Smith, T. L. and Kummerow, F. A., Effect of dietary fats on desaturase activities and biosynthesis of fatty acids in rat liver microsomes. Lipids, 1984, 19(3), 214-222.

[77] Maniongui, C., Blond, J. P., Durand, G., Poisson, J. P. and Bezard, J., Age-related changes in D6 and D5 desaturase activities in rat liver microsomes. Lipids, 1993, 28(4), 291-297.

[78] Markesby, W. R., Oxidative stress hypothesis in Alzheimer's disease. Free Rad. Biol. Med., 1997, 23, 134-147.

[79] Marteinsdottir, I., Horrobin, D. F., Stenfors, C., Theodorsson, E. and Mathe, A. A., Changes in dietary fatty acids alter phospholipid fatty acid composition in selected regions of rat brain. Prog. Neuro-Psychopharm. Biol. Psych., 1998, 22(6), $1007-1021$.

[80] Martin, R. E., Docosahexaenoic acid decreases phospholipase A2 activity in the neurites/nerve growth cones of PC12 cells. $J$. Neurosci. Res., 1998, 15(54), 805-813.

[81] Martin, R. E. and Bazan, N. G., Changing fatty acid content of growth cone lipids prior to synaptogenesis. J. Neurochem., 1992, 59(1), 318-325.

[82] Mason, R. P., Walter, M. F. and Mason, P. E., Effect of oxidative stress on membrane structure: small angle X-ray diffraction analysis. Free Rad. Biol. Med., 1997, 23, 419-425.

[83] Mayatepek, E. and Hoffman, G., Leukotrienes: biosynthesis, metabolism, and pathophysiological significance. Ped. Res., 1995, 37, 1-9.

[84] McGee, C. D., Greenwood, C. E. and Cinader, B., Dietary fat composition and age affect synaptosomal and retinal phospholipid fatty acid composition in C57BL/6 mice. Lipids, 1994, 29(9), 605-610.

[85] McGeer, P. L. and McGeer, E. G., The inflammatory response system of the brain: implications for therapy of Alzheimer and other neurodegenerative diseases. Brain Res. Rev., 1995, 21, 195-218.

[86] McMillin, J. B., Bick, R. J. and Benedict, C. R., Influence of dietary fish oil on mitochondrial function and response to ischemia. Am. J. Physiol., 1992, 263, 1479-1485.

[87] Minami, M., Kimura, S., Endo, T., Hamaue, N., Hirafuji, M.,
Togashi, H., Maysumoto, M., Yoshioka, M., Saito, H., Watanabe, S., Kobayashi, T. and Okuyama, H., Dietary docosahexaenoic acid increases cerebral acetylcholine levels and improves passive avoidance performance in stroke-prone spontaneously hypersensitve rats. Pharmacol. Biochem. Behav., 1997, 58(4), 1123-1129.

[88] Moussa, M., Garcia, J., Ghisolfi, J., Periquet, B. and Thouvenot, J. P., Dietary essential fatty acid deficiency differentially affects tissues of rats. J. Nutr., 1996, 126(12), 30403045.

[89] Murphy, M. G., Wright, V., Ackman, R. G. and Horackova, M., Diets enriched in menhaden fish oil, seal oil, or shark liver oil have distinct effects on the lipid fatty acid composition of guinea pig heart. Mol. Cell Biochem., 1997, 177, 257-269.

[90] Naveilhan, P., Neveu, I., Jehan, F., Baudet, C., Wion, D. and Brachet, P., Reactive oxygen species influence nerve growth factor synthesis in primary rat astrocytes. J. Neurochem., 1994, 62, 2178-2186.

[91] Neuringer, M., Connor, W. E., Lin, D. S., Barstad, L. and Luck, S., Biochemical and functional effects of prenatal and postnatal omega 3 fatty acid deficiency on retina and brain rhesus monkeys. Proc. Natl. Acad. Sci. USA, 1986, 83(11), 4021-4025.

[92] Nieuwenhuys, C. M. and Hornstra, G., The effects of purified eicosapentaenoic and docosahexaenoic acids on arterial thrombosis and platelet function in rats. Biochim. Biophys. Acta, 1998, 1390(13), 313-322.

[93] Node, K., Huo, Y., Ruan, X., Yang, B., Spieker, M., Ley, K., Zeldin, D. C. and Liao, J. K., Anti-inflammatory properties of cytochrome P450 epoxygenase-derived eicosanoids. Science, 1999, 20(285), 1276-1279.

[94] Nouvelot, A., Bourre, J. M., Sezille, G., Dewailley, P. and Jaillard, J., Changes in the fatty acids patterns of brain phospholipids during development of rats fed peanut or rapeseed oils, taking into account differences between milk and maternal food. Ann. Nutr. Metab., 1983, 27, 173-182.

[95] O'Farrell, S. and Jackson, M. J., Dietary polyunsaturated fatty acids, vitamin $\mathrm{E}$ and hypoxia/reoxygenation-induced damage to cardiac tissue. Clin. Chim. Acta, 1997, 267(2), 197211.

[96] Obukowicz, M. G., Welsch, D. J., Salsgiver, W. J., MartinBerger, C. L., Chinn, K. S., Duffin, K. L., Raz, A. and Needleman, P., Novel, selective delta6 or delta5 fatty acid desaturase inhibitors as antiinflammatory agents in mice. $J$. Pharmacol. Exp. Ther., 1998, 287(1), 157-166.

[97] Ochi, K., Yoshimoto, T., Yamamoto, S., Tangiguche, K. and Miyamoto, T., Arachidonate 5-lipoxygenase on guinea pig peritoneal polymorphonuclear leukocytes. J. Biol. Chem., 1983, 258, 5754-5758.

[98] Okusawa, S., Gelfand, J., Ikejima, T., Connolly, R. and Dinarello, C., Interleukin 1 induces a shock-like state in rabbits. Synergism with tumor necrosis factor and the effect of cyclooxygenase inhibition. J. Clin. Invest., 1988, 81(4), 11621172.

[99] Okuyama, H., Minimum requirements of n-3 and n-6 essential fatty acids for the function of the central nervous system and for the prevention of chronic disease. Proc. Soc. Exp. Biol. Med., 1992, 200(2), 174-176.

[100] Otten, W., Iaizzo, P. A. and Eichinger, H. M., Effects of a high n-3 fatty acid diet on membrane lipid composition of heart and skeletal muscle in normal swine and in swine with the genetic mutation for malignant hyperthermia. J. Lipid. Res., 1997, 38(10), 2023-2034.

[101] Parks, J. S., Kaduck-Sawyer, J., Bullock, B. C. and Rudel, L. L., Effect of dietary fish oil on coronary artery and aoritc atherosclerosis in African green monkeys. Arteriosclerosis, 1990, 10(6), 1102-1112. 
[102] Pearce, R., Owen, A., Daniel, S., Jenner, P. and Marsden, C., Alterations in the distribution of glutathione in the substantia nigra in Parkinson's disease. J. Neural Transmis., 1997, 104(67), 661-677.

[103] Pepe, S., Tsuchiya, N., Lakatta, E. G. and Hansford, R. G., PUFA and aging modulate cardiac mitochondrial membrane lipid composition and $\mathrm{Ca} 2+$ activation of DPH. Am. J. Physiol., 1999, 276, H149-H158.

[104] Pezzella, A., d'Ischia, M., Misuraca, G. and Prota, G., Ironmediated generation of the neurotoxin 6-hydroxydopamine quinone by reaction of fatty acid hydroproxides with dopamine: a possible contributory mechanism for neuronal degeneration in Parkinson's disease. J. Med. Chem., 1997, 40, 2211-2216.

[105] Piomelli, D., Eicosanoids in synaptic transmission. Critical Rev. Neurobiol., 1999, 8(12), 65-83.

[106] Prasad, M. R., Lovell, M. A., Yatin, M., Dhillon, H. and Markesbery, W. R., Regional membrane phospholipid alterations in Alzheimer's disease. Neurochem. Res., 1998, 23, 81-88.

[107] Procopio, D. O., Teixeira, M. M., Camargo, M. M., Travassos, L. R., Ferguson, M. A., Almeida, I. C. and Gazzinelli, R. T., Differential inhibitory mechanism of cyclic AMP on TNF-alpha and IL-12 synthesis by macrophages exposed to microbial stimuli. Br. J. Pharmacol., 1999, 127(5), 1195-1205.

[108] Quoc, K. P. and Pascaud, M., Effects of dietary gamma-linolenic acid on the tissue phospholipid fatty acid composition and the synthesis of eicosanoids in rats. Ann. Nutr. Metab., 1996, 40(2), 99-108.

[109] Racay, P., Matejovicova, M., Drgova, A., Dobrota, D., Kaplan, P., Lehotsky, J. and Mezesova, V., The effect of ischemia and ischemia-reperfusion on ion transport systems. Bratisl. Lek. Listy., 1998, 99(7), 386-394.

[110] Rao, G., Lassegue, B., Griendling, K. and Alexander, R., Hydrogen peroxide stimulates transcription of c-jun in vascular smooth muscle cells: role of arachidonic acid. Oncogene., 1993, 8(10), 2759-2764.

[111] Reinboth, J. J., Clausen, M. and Reme, C. E., Light elicits the release of docosahexaenoic acid from membrane phospholipids in the rat retina in vitro. Exp. Eye Res., 1996, 63(3), 277-284.

[112] Rordorf, G., Uemura, Y. and Bonventre, J. V., Characterization of phospholipase A2 (PLA2) activity in gerbil brain: enhanced activities of cytosolic, mitochondrial and microsomal forms after ischemia and reperfusion. J. Neurosci., 1991, 11(6), 1829-1836.

[113] Rosenman, S. J., Shrikant, P., Dubb, L., Benveniste, E. N. and Ransohoff, R. M., Cytokine induced expression of vascular cell adhesion molecule-1 (VCAM-1) by astrocytes and astrocytoma cell lines. J. Immunol., 1995, 154, 1888-1899.

[114] Saito, M. and Yamaguchi, M., Liver microsomal mixed-function oxidases in response to polyunsaturated/saturated and n6/n-3 fatty acid ratios of dietary lipids in rats. Ann. Nutr. Metab., 1994, 38(1), 28-39.

[115] Sala, A., Zarini, S. and Bolla, M., Leukotrienes: lipid bioeffectors of inflammatory reactions. Biochem., 1998, 63(1), 84-92.

[116] Salem, N., Omega-3 fatty acids: molecular and biochemical aspects. In New Protective Roles for Selected Nutrients. Alan R. Liss, New York, 1989, pp. 109-228.

[117] Salem, N. J. and Niebylski, C. D., The nervous system has an absolute molecular species requirement for proper function. Mol. Membr. Biol., 1995, 12(1), 131-134.

[118] Sawazaki, S., Salem, N. J. and Kim, H. Y., Lipoxygenation of docosahexaenoic acid by the rat pineal body. J. Neurochem., 1994, 62(6), 2437-2447.

[119] Schror, K., The effect of prostaglandins and thromboxane $A_{2}$ on coronary vessel tone - mechanisms of action and therapeutic implications. Eur. Heart J., 1993, 14(suppl 1), 34-41.
[120] Shikano, M., Masuzawa, Y. and Yazawa, K., Effect of docosahexaenoic acid on the generation of platelet-activating factor by eisinophilic leukemia cells, Eol-1. J. Immunol., 1993, 15(150), 3525-3533.

[121] Shimizu, T. and Wolfe, L., Arachidonic acid cascade and signal transduction. J. Neurochem., 1990, 55(1), 1-15.

[122] Shukitt-Hale, B., Bickford, P. C., McEwen, J. J., Cao, G., Prior, R. L. and Joseph, J. A., Reversal of Age-related Motor and Cognitive Behavioral Deficits with Diets Supplemented with Fruit or Vegetable Extracts. Society For Neuroscience, 1998, Washington, DC.

[123] Simonian, N. A. and Coyle, J. T., Oxidative stress in neurodegenerative diseases. Ann. Rev. Pharmacol. Toxicol., 1996, 36, 83-106.

[124] Simopoulos, A. P. and Salem, N., Purslane; a terrestrial source of n-3 fatty acids. N. Engl. J. Med., 1986, 315, 833-839.

[125] Slater, S. J., Kelly, M. B., Yeager, M. D., Larkin, J., Ho, C. and Stubbs, C. D., Polyunsaturation in cell membranes and lipid bilayers and its effects on membrane properties. Lipids, 1996, 31, S189-S192.

[126] Smith, W., Prostanoid biosynthesis and mechanisms of action. Am. J. Physiol., 1992, 263(2), F181-F191.

[127] Sprecher, H., Interactions between metabolism of n-6 and n-3 fatty acids. J. Int. Med., 1989, 225, 5-11.

[128] Srinivasarao, P., Narayanareddy, K., Vajreswari, A., Rupalatha, M., Prakash, P. S. and Rao, P., Influence of dietary fat on the activities of subcellular membrane-bound enzymes from different regions of the brain. Neuochem. Int., 1997, 31(6), 789-794.

[129] Stiefel, P., Ruiz-Gutierrez, V., Gajn, E., Acosta, D., GarciaDonas, M. A., Madrazo, J., Villar, J. and Carneado, J., Sodium transport kinetics, cell membrane lipid composition, neural conduction and metabolic control in type 1 diabetic patients, changes after a low-dose n-3fatty acid dietary intervention. Ann. Nutr. Metab., 1999, 43(2), 113-120.

[130] Stillwell, W., Ehringer, W. and Jenski, L. J., Docosahexaenoic acid increases permeability of lipid vesicles and tumor cells. Lipids, 1993, 28(2), 103-108.

[131] Stillwell, W., Jenski, L. J., Crump, F. T. and Ehringer, W., Effect of docosahexaenoic acid on mouse mitochondrial membrane properties. Lipids, 1997, 32(5), 497-506.

[132] Sun, D. and Gilboe, D. D., Ischemia-induced changes in cerebral mitochondrial free fatty acids, phospholipids, and respiration in the rat. J. Neurochem., 1994, 62(5), 1921-1928.

[133] Suzuki, H., Park, S. J., Tamura, M. and Ando, S., Effect of the long-term feeding of dietary lipids on the learning ability, fatty acid composition of brain stem phospholipids and synaptic membrane fluidity in adult mice: a comparison of sardine oil diet with palm oil diet. Mech. Ageing Dev., 1998, 16(101), 119-128.

[134] Tahin, Q. S., Blum, M. and Carafoli, E., The fatty acid composition of subcellular membranes of rat liver, heart and brain: diet-induced modifications. Eur. J. Biochem., 1981, 121, $5-13$.

[135] Tinoco, J., Dietary requirements and functions of alpha-linolenic acid in animals. Prog. Lipid. Res., 1982, 21, 1-45.

[136] Tinoco, J., Babcock, R., Hincenbergs, I. and Medwadowski, B., Linoleic acid deficiency: changes in fatty acid patterns in female and male rats on a linolenic acid-deficient diet for two generations. Lipids, 1978, 13, 6-12.

[137] Tirosh, O., Kohen, R., Katzhendler, J., Alon, A. and Barenholz, Y., Oxidative stress effect in the integrity of lipid bilayers is modulated by cholesterol level of bilayers. Chem. Phys. Lipids, 1997, 87, 17-22.

[138] Toborek, M., Blanc, E. M., Kaiser, S., Mattson, M. P. and Hennig, B., Linoleic acid potentiates TNFa-mediated oxidative stress, disruption of calcium homeostasis, and apoptosis of cul- 
tured vascular endolthelial cells. J. Lipid Res., 1997, 38, 21552167.

[139] Tomoike, H., Egashira, K., Yamada, A., Hayashi, Y. and Nakamura, M., Leukotriene $\mathrm{C}_{4}$ and $\mathrm{D}_{4}$-induced diffuse peripheral constriction of swine coronary artery accompanied by ST elevation on the electrocardiogram. Circulation, 1987, 76, 480487.

[140] Trapp, B. D. and Bernsohn, J., Essential fatty acid deficiency and CNS myelin. Biochemical and morphological observations. J. Neurol., 1978, 37, 249-266.

[141] Tsuji, F., Miyake, Y., Horiuchi, M. and Mita, S., Involvement of leukotriene B4 in murine dermatitis models. Biochem. Pharmacol., 1998, 55(3), 297-304.

[142] Tsuji, F., Oki, K., Fujisawa, K., Okahara, A., Horiuchi, M. and Mita, S., Involvement of leukotriene B4 in arthritis models. Life Sci., 1999, 64(3), PL51-PL56.

[143] Tsutsumi, T., Yamauchi, E., Suzuki, E., Watanabe, S., Kobayashi, T. and Okuyama, H., Effect of a high alpha-linolenate and high linoleate diet on membrane associated enzyme activities in rat brain-modulation of $\mathrm{Na}+, \mathrm{K}+$ ATPase activity at suboptimal concentrations of ATP. Biol. Pharm. Bull., 1995, 18(5), 664-670.

[144] Turpeinen, A. M., Basu, S. and Mutanen, M., A high linoleic acid diet increases oxidative stress in vivo and affects nitric oxide metabolism in humans. Prostaglan. Leukotr. Essen. Fatty Acids, 1998, 59, 229-233.

[145] Urano, S., Sato, Y., Otonari, T., Makabe, S., Susuki, S., Ogata, M. and Endo, T., Aging and oxidative stress in neurodegeneration. Biofactors, 1998, 7, 103-112.

[146] van Houwelingen, A. C., Puls, J. and Hornstra, G., Essential fatty acid status during early human development. Early Hum. Dev., 1992, 31, 97-111.

[147] van Kooten, F., Ciabattoni, G., Koudstaal, P. J., Grobbee, D. E., Kluft, C. and Patrono, C., Increased thromboxane biosynthesis is associated with poststroke dementia. Stroke, 1999, 30(8), 1542-1547.

[148] Venkatraman, J. T., Angekeow, P., Satsangi, N. and Ferandes, G., Effects of dietary n-6 and n-3 lipids on antioxidative defence system in livers of exercised rats. J. Am. Coll. Nutr., 1998, 17, 586-594.

[149] Vericel, E., Croset, M., Perrot, L., Renaud, S. and Lagarde, M., Platelets and aging II- Plasma lipoproteins and fatty acids profiles. Thromb. Res., 1998, 22(49), 451-455.

[150] Viani, P., Cervato, G., Fiorilli, A. and Cestaro, B., Age-related differences in synaptosomal peroxidative damage and membrane properties. J. Neurochem., 1991, 56(1), 253-258.

[151] Voss, A., Reinhart, M., Sankarappa, S. and Sprecher, H., The metabolism of $7,10,13,16,19$-docosapentaenoic acid to 4,7 , $10,13,16,19$-docosahexaenoic acid in rat liver is independent of a 4-desaturase. J. Biol. Chem., 1991, 266(30), 19,995-20,000.

[152] Vreugdenhil, M., Bruehl, C., Voskuyl, R. A., Kang, J. X., Leaf, A. and Wadman, W. J., Polyunsaturated fatty acids modulate sodium and calcium curents in CA1 neurons. Proc. Natl. Acad. Sci. USA, 1996, 93(22), 12,559-12,563.

[153] Wainwright, P. E., Xing, H., Ward, G. R., Bobik, E., Austad, N. and Montalto, M., Water maze performance is unaffected in artificially reared rats fed diets supplemented with arachidonic acid and docosahexaenoic acid. J. Nutr., 1999, 129(5), 1079-1089.

[154] Wakatsuki, A., Izumiya, C., Okatani, Y. and Sagara, Y., Oxidative damage in fetal rat brain induced by ischemia and subsequent reperfusion. Relation to arachidonic acid peroxidation. Biol. Neonate, 1999, 76(2), 84-91.

[155] Weisinger, H. S., Vingrys, A. J. and Sinclair, A. J., Dietary manipulation of long-chain polyunsaturated fatty acids in the retina and brain of guinea pigs. Lipids, 1995, 30(5), 471-473.

[156] Willumsen, N., Vaagenes, H., Lie, O., Rustan, A. C. and Berge, R. K., Eicosapentaenoic acid, but not docosahexaenoic acid, increases mitochondrial fatty acid oxidation and upregulates 2,4-dienoyl-CoA reductase gene expression in rats. Lipids, 1996, 31(6), 579-592.

[157] Wolfe, M. S., Sawyer, J. K., Morgan, T. M., Bullock, B. C. and Rudel, L. L., Dietary polyunsaturated fat decreases coronary artery atherosclerosis in a pediatric-aged population of African green monkeys. Arterioscler. Thromb., 1994, 14(4), $587-597$.

[158] Woodroofe, M. N., Cytokine production in the central nervous system. Neurol., 1995, 45, S6-S10.

[159] Yamamoto, N., Okaniwa, Y., Mori, S., Nomura, M. and Okuyama, H., Effects of high-linoleate and a high alpha-linolenate diet on the learning ability of aged rats. Evidence against an autoxidation-related lipid peroxide theory of aging. $J$. Gerontol., 1991, 46(1), 17-22.

[160] Youdim, K. A. and Deans, S. G., Beneficial effects of thyme oil on age-related changes in phospholipid C20 and C22 polyunsaturated fatty acid composition of various rat tissues. Biochim. Biophys. Acta, 1999, 1438, 140-146.

[161] Youdim, K. A. and Deans, S. G., Effect of thyme oil and thymol dietary supplementation on the antioxidant status and fatty acid composition of the ageing rat brain. Brit. J. Nutr., 1999, in Press.

[162] Zhang, L., The effects of essential fatty acids preparation in the treatment of intrauterine growth retardation. Am. J. Perinatol., 1997, 14(9), 535-537. 